\title{
The effects of self-management interventions on depressive symptoms in adults with chronic physical disease(s) experiencing depressive symptomatology: a systematic review and meta-analysis
}

\author{
Lydia Ould Brahim $^{1 *}$ (D), Sylvie D. Lambert ${ }^{1,2}$, Nancy Feeley ${ }^{1,3}$, Chelsea Coumoundouros ${ }^{4}$, Jamie Schaffler ${ }^{2}$,
} Jane McCusker ${ }^{2,5}$, Erica E. M. Moodie ${ }^{6}$, John Kayser ${ }^{7}, K^{2}$.

\begin{abstract}
Background: Chronic diseases are the leading cause of death worldwide. It is estimated that $20 \%$ of adults with chronic physical diseases experience concomitant depression, increasing their risk of morbidity and mortality. Low intensity psychosocial interventions, such as self-management, are part of recommended treatment; however, no systematic review has evaluated the effects of depression self-management interventions for this population. The primary objective was to examine the effect of self-management interventions on reducing depressive symptomatology in adults with chronic disease(s) and co-occurring depressive symptoms. Secondary objectives were to evaluate the effect of these interventions on improving other psychosocial and physiological outcomes (e.g., anxiety, glycemic control) and to assess potential differential effect based on key participant and intervention characteristics (e.g., chronic disease, provider).

Methods: Studies comparing depression self-management interventions to a control group were identified through a) systematic searches of databases to June 2018 [MEDLINE (1946 -), EMBASE (1996 -), PsycINFO (1967 -), CINAHL (1984 -)] and b) secondary 'snowball' search strategies. The methodological quality of included studies was critically reviewed. Screening of all titles, abstracts, and full texts for eligibility was assessed independently by two authors. Data were extracted by one author and verified by a second.

Results: Fifteen studies were retained: 12 for meta-analysis and three for descriptive review. In total, these trials included 2064 participants and most commonly evaluated interventions for people with cancer $(n=7)$ or diabetes $(n=4)$. From baseline to $<6$-months $(\mathrm{T} 1)$, the pooled mean effect size was $-0.47[95 \% \mathrm{Cl}-0.73,-0.21]$ as compared to control groups for the primary outcome of depression and -0.53 [95\% Cl -0.91, - 0.15] at $\geq 6$-months (T2). Results were also significant for anxiety (T1) and glycemic control (T2). Self-management skills of decision-making and taking action were significant moderators of depression at $\mathrm{T} 1$.
\end{abstract}

\footnotetext{
* Correspondence: lydia.oulbrahim@mail.mcgill.ca

${ }^{1}$ Ingram School of Nursing, McGill University, Montreal, Canada

Full list of author information is available at the end of the article
}

(c) The Author(s). 2021 Open Access This article is licensed under a Creative Commons Attribution 4.0 International License, which permits use, sharing, adaptation, distribution and reproduction in any medium or format, as long as you give appropriate credit to the original author(s) and the source, provide a link to the Creative Commons licence, and indicate if changes were made. The images or other third party material in this article are included in the article's Creative Commons licence, unless indicated otherwise in a credit line to the material. If material is not included in the article's Creative Commons licence and your intended use is not permitted by statutory regulation or exceeds the permitted use, you will need to obtain permission directly from the copyright holder. To view a copy of this licence, visit http://creativecommons.org/licenses/by/4.0/. The Creative Commons Public Domain Dedication waiver (http://creativecommons.org/publicdomain/zero/1.0/) applies to the data made available in this article, unless otherwise stated in a credit line to the data. 
Conclusion: Self-management interventions show promise in improving depression and anxiety in those with concomitant chronic physical disease. The findings may contribute to the development of future Self-management interventions and delivering evidence-based care to this population. Further high-quality RCTs are needed to identify sources of heterogeneity and investigate key intervention components.

Keywords: Self-management, Chronic disease, Depression, Anxiety, Decision-making, Systematic review

\section{Background}

\section{Prevalence and impact of depression in adults with} chronic disease(s)

Depression affects 300 million people and is currently the leading cause of mortality worldwide substantially impacting social and occupational functioning [1-4]. Prevalence of depression is more common among individuals with chronic physical diseases $[2,3,5]$. Estimates indicate that approximately $20 \%$ of people with chronic physical diseases experience depression, at least twice the rate found in the general population [5-7].

Chronic diseases are increasingly prevalent and are currently estimated to account for $60 \%$ of all deaths worldwide $[8,9]$. Studies have demonstrated that depression has a significant impact on the course and health outcomes of concomitant chronic physical diseases and complicates treatment [5, 6]. For example, depression has been shown to amplify somatic symptoms and diminish self-efficacy of health-related behaviours $[6,10$, 11]. Furthermore, in addition to major depressive disorder, sub-threshold depression is associated with negative outcomes including increased morbidity in those with co-occurring physical diseases, and is also a risk factor for major depression [12-14].

\section{Self-management interventions for depression}

It is recognized that timely treatment of depression is likely to improve functional ability, quality of life, and will considerably reduce the burden of chronic physical disease on the care recipient $[15,16]$. However, worldwide less than half of those affected by depression receive adequate treatment, as there is often limited care available or barriers to accessing it, particularly high cost and lack of mental health professionals $[12,17,18]$. In response to the need for more depression support, one cost-efficient option that has shown promise is self-management interventions. Self-management interventions for depression have been formally incorporated into many healthcare systems and are recommended in best practice guidelines [19-21]. The only guidelines specifically targeting the treatment of depression in those with concomitant chronic physical disease(s), recommend self-management interventions for the treatment of mild to moderate depressive symptoms or as adjunctive therapy in the case of more severe symptoms [22]. However, to our knowledge, no systematic review has evaluated the effects of depression self-management interventions across chronic physical disease populations.

Self-management refers to the tasks an individual must undertake to live well with their chronic disease(s) $[23,24]$. Generally, these tasks involve: a) medical management; b) maintaining, changing, or developing new meaningful behaviours; and c) dealing with the emotional impacts of the disease(s) [25]. In self-management, the individual's role in their own care is considered central and the individual takes on the responsibility, as much as possible, of developing the necessary skills to manage their symptoms.

Self-management includes more than providing health or disease-related information, rather it is focused on behaviour change through the development of the skills and confidence needed for successful self-management of chronic disease [26, 27]. This is usually accomplished through the use of psychoeducational or behaviour strategies [28]. Learning these self-management skills can be done independently or in collaboration with health care professionals (HCPs) or a non-professional, often peer, support person $[25,29]$.

Arguably the most robust conceptualization of self-management is that articulated by Drs. Lorig and Holman based on nearly 25 years of work in the area $[25,30,31]$. This theoretically informed research indicates that self-management involves core skills (e.g., problem-solving, decision-making) that can be applied across chronic diseases [25, 32, 33]. From this perspective, self-management is not considered disease specific, but is focused on the development of broad skills, and self-management programs may therefore include people with a variety of chronic diseases [32, 33]. Additional skills may also be targeted when supporting the learned management of particular diseases. Aligned with this, based on existing literature, self-management skills specific to depression have been identified including behavioural activation (e.g., increasing positive activities) and social support (see Appendix A for details and references). 


\section{Self-management, self-help, cognitive behavioural therapy, and self-care}

A number of terms are often incorrectly used interchangeably with self-management, including self-help, cognitive behavioural therapy (CBT), and self-care. In comparison to self-management self-help encompasses a much broader range of interventions that are primarily self-directed (e.g., books, smartphone application). Self-help interventions are predominantly designed to limit contact with HCPs [34]. On the other hand, self-management interventions focus on specific skills and are often conducted in close collaboration with HCPs, although some may be self-directed [25]. Though many self-management interventions use principles of cognitive behavioural therapy (CBT), these are also distinct [29]. Self-management is one of the essential elements of the Chronic Care Model (CCM), an evidence-based guide to chronic disease management in primary care [26, 35]. Selfmanagement interventions employ psychoeducational and/ or behavioural strategies to assist care recipients and families develop the skills and confidence necessary to live well with a chronic disease (e.g., learning to locate resources, forming partnerships with HCPs) $[25,36]$. Self-management is not a form of psychotherapy and rather than delivered by a therapist, self-management can be delivered by a variety of HCPs (e.g., it not a protected act) or as a self-directed intervention.

Finally, self-care is also frequently used interchangeably with self-management; however, they may be delineated on several fronts. Self-care involves managing one's health, with or without a chronic condition. It also encompasses a broad range of strategies including 'doing nothing.' Another marked difference is that self-care does not usually involve HCP support and focuses primarily on health promotion or the prevention of disease or accident [37]. In contrast, as an element of the CCM, self-management was developed specifically for people with chronic disease and centres on the development of evidence-based skills [25, 28, 37].

\section{Aims of this Review}

Accounting for the issues outlined above, the primary objective of this review is to determine the effects of self-management interventions on reducing depressive symptomatology among adults with chronic physical disease(s) and co-occurring depressive symptoms. The secondary objectives are:

a) To determine whether the effects of self-management interventions on the primary outcome of depressive symptoms vary depending on the participants' cooccurring chronic physical disease and baseline level of depressive symptoms (e.g., mild, moderate).

b) To assess whether the interventions reviewed have differential effects on the primary outcome of depressive symptoms depending on intervention characteristics and content: the type and number of self-management skills targeted, mode of delivery (e.g., face-to-face, online), type and intensity of guidance, intervention provider, format (e.g., group or individual), and duration (minutes of participation) and length of time over which the intervention was delivered.

c) To assess the effects of self-management interventions on other physiological and psychosocial outcomes (e.g., quality of life, fatigue) among the target population.

\section{Methods \\ Methodological framework}

The methods for this review were developed following the recommendations of the Cochrane Handbook for Systematic Reviews of Interventions [38] and the Preferred Reporting Items for Systematic Reviews and Meta-Analyses (PRISMA) statement [39]. The protocol was registered with the prospective register of systematic reviews (PROSPERO CRD42019132215).

\section{Criteria for considering studies for this review Types of studies}

Published or in press peer-reviewed full-text randomized controlled trials (RCTs) as well as cross-over trials and studies using a quasi-experimental design (e.g., controlled trials without randomization, but with a comparison group) were considered for inclusion in this review. To be eligible, the primary outcome (depressive symptoms) had to be measured pre- and post-intervention and only English and French language articles were included. Conference abstract and theses were excluded.

\section{Types of participants and settings}

Based on Lorig and Holman's [25] conceptualization of self-management, participants with various chronic diseases were included. The target population for this review was adults (over age 18) with chronic physical disease(s) experiencing at least mild depressive symptoms according to a validated scale or clinical interview. The following psychometrically validated questionnaires and cut-off scores indicating at least mild depressive symptoms were eligible for inclusion:

- Beck Depression Inventory (scores $\geq 10)[40,41]$

- Beck Depression Inventory-II (scores $\geq 13$ ) [42]

- Centre for Epidemiological Studies - Depression (scores $\geq 16$ ) $[43,44]$

- Centre for Epidemiological Studies - Depression 10item version (scores $\geq 10$ ) $[45,46]$

- Hamilton Depression Rating Scale - Depression subscale (scores $\geq 8$ ) [47]

- Hospital Anxiety and Depression Scale - Depression (scores $\geq 8$ ) [48] 
- Patient Health Questionnaire (scores $\geq 5$ ) [49]

- Geriatric Depression Scale (scores $\geq 11$ ) [50]

In terms of clinical interviews, the DSM-III (Diagnostic and Statistical Manual of Mental Disorders) and above [51-55] as well as the ICD-9 (International classification of diseases) and above $[56,57]$ were considered eligible.

Studies including participants with one or multiple chronic physical diseases as defined by the Public Health Agency of Canada (excluding dementia) and World Health Organization were included $[9,58]$. Participants taking anti-depressant medication were eligible, if pharmacotherapy was not administered as part of the intervention being evaluated. In terms of co-morbidities, studies including participants with a diagnosis of bipolar disorder, post-partum depression, seasonal affective disorder, or post-traumatic stress disorder were excluded as the etiology, disease course, and treatment recommendations for these conditions differ from depression [5962]. No limits were placed on the setting in which the study was conducted.

\section{Types of interventions}

Experimental interventions. Studies evaluating selfmanagement interventions for depressive symptoms were included. Interventions were eligible if they incorporated at least one of the key self-management skills described in Appendix A. These skills were derived from the theoretical literature as well as from existing selfmanagement interventions from reputable (peerreviewed or government issued) sources [25, 29, 63-65]. Further, the intervention had to be administered to the individual directly. Interventions in which the person with the chronic disease participated with someone else (e.g., family member) were excluded due to the confounding effects of social support [66].

Multi-component interventions were eligible as a long as the above self-management criteria were met and at least one component targeted mood, distress, or depression. To avoid confounding effects, studies evaluating interventions including a component in which pharmacotherapy was administered were excluded. All formats of interventions were eligible (e.g., workbooks, online modules). Level of guidance by HCPs was not an exclusion criterion; self-directed, minimal contact, and HCP administered interventions were all eligible.

Comparator interventions. Eligible control comparisons were no treatment, treatment as usual, waitlist, and attention control groups, as long as the participants were not receiving active components of the interventions (e.g., psychological therapy or the self-management skills outlined in Appendix A).

\section{Outcome measures}

The primary outcome was depressive symptoms. The secondary outcomes were a) improvement in psychosocial outcomes such as quality of life, anxiety, selfmanagement skills, and self-efficacy; b) improvement in physical health measures; c) improvement in alcohol and drug consumption; and/or d) decrease in health care utilization.

\section{Information sources and study selection Search strategies}

Eligible studies were primarily identified through searches of electronic bibliographic databases. Secondary search strategies consisted of verifying the reference lists of the included full-texts and using the PubMed 'find similar' function. Unpublished findings were also sought through the Cochrane library as well as the national and international trial registries outlined in the Cochrane Handbook for Systematic Reviews [38]. These were searched for relevant trial protocols and, if published findings of these trials could not be found, authors were contacted directly for further information.

\section{Database searches}

Eligible studies were identified by searching the following databases: MEDLINE (1946-), EMBASE (1996 -), PsycINFO (1967 -), and Cumulative Index to Nursing \& Allied Health (CINAHL) (1984 -). The search was conducted in June 2018 and no limits were applied. All databases were searched using a combination of keywords and subject headings across three concepts: a) selfmanagement, b) depression, and c) trial design (RCT or quasi-experimental). The search strategy was developed in consultation with a health sciences librarian and were assessed using the Peer Review for Electronic Search Strategies (PRESS) guidelines [67]. The full primary electronic search for Ovid Medline is included in Appendix B. All titles and abstracts were downloaded to a citation manager, EndNote, and screened using Rayyan online software. Duplicates were removed according to the procedures outlined in Bramer, Giustini [68].

\section{Study selection}

Two authors independently assessed the eligibility of all retrieved titles, abstracts, and full texts to confirm inclusion or exclusion. Two authors also separately examined the reference lists of included full texts. Finally, searches were conducted using the 'find similar' function of PubMed. Any disagreements were discussed with a third 
author until consensus was established. Multiple reports relating to the same study were aggregated so that findings reflected each study rather than each report.

\section{Data extraction}

Data were extracted using a standardized Microsoft Excel form that was developed based on the Cochrane Handbook for Systematic Reviews [38]. The form was adapted from one used in a previous systematic review conducted by team members $[69,70]$. Data were extracted by one author and confirmed by at least one other. Disagreements were discussed with a third author until resolved.

The following data on study characteristics were extracted: citation details, country of origin, study design, aims, theoretical framework, population (age, diagnosis, gender, depressive symptoms), sample size, setting (e.g., hospital, community), summary of intervention and control groups, self-management skills in the intervention, format of the intervention, intervention provider, level of guidance, duration of the intervention (number of minutes of participation), length of intervention (time period over which the intervention was delivered, e.g., 2-months of sessions), monitoring of fidelity and adherence, outcomes, timing of measurement, and attrition [38]. Outcomes were grouped into two time periods: T1 from baseline $<6$ months post-baseline and $\mathrm{T} 2 \geq 6$-months post-baseline. If any data were missing or unclear, the authors of the manuscript were contacted for further information.

\section{Methodological quality}

Two authors (combination of the first, seventh, and eight authors) independently assessed the risk of bias of each study based on the criteria outlined in the Cochrane Risk of Bias tool [71]. Again, disagreements were discussed with a third author until consensus was reached. The risk of bias was evaluated according to the following criteria: a) inclusion criteria specified, b) pre-specified primary outcome(s), c) psychometric properties of primary outcomes provided, d) explicit power calculation, e) target sample size reached, f) appropriate randomization procedures and allocation concealment, g) discussion of potential cointerventions, h) baseline characteristics of all groups provided, i) blinding of outcome assessors, participants, and interventionists, $\mathrm{j}$ ) adherence to intervention (> 75\%), k) fidelity monitoring, l) management of missing data (intention-to-treat analysis), m) participant retention (> $80 \%$ ), and $\mathrm{n}$ ) reasons for attrition stated.

Each potential source of bias was evaluated as having been met (score 1) or not met (score 0 ). If the information was not specified in the manuscript the authors were contacted. If the information could not be clarified, the item was deemed not to have been met. Studies were considered to be of high methodological quality if $13-17$ of the criteria were met, moderate quality if $8-12$ were met, and low fewer than 8 were met. Direct quotes from each study as well as supporting comments were included in the evaluation of each. For evidence of selective reporting, study protocols or trial registration of included articles, when available, were compared to the published findings and unexplained discrepancies were noted [71].

\section{Data analysis}

Effect sizes (Hedge's adjusted g) were calculated using outcome scores at post-intervention assessment between treatment and control conditions for the T1 and $\mathrm{T} 2$ time periods $[38,72]$. Initially analyses were planned for three time periods: $\mathrm{T} 1<3$ months post-baseline, T2 -3 to $<6$ months post-baseline, and T3 $\geq 6$ months post-baseline. Due to the limited sample size, T1 and T2 were combined. Hedge's adjusted $g$ was selected to reduce potential bias due to small sample sizes [73]. The magnitude of the effect size can be interpreted according to the benchmarks outlined by Cohen (1988) [74]; namely, small (0.2), moderate (0.5), and large (0.8).

Pooled mean effect sizes were calculated to obtain a summary statistic for the $\mathrm{T} 1$ and $\mathrm{T} 2$ periods. If a study reported both per protocol and intention-to-treat analyses, per protocol data were included in the meta-analysis. When outcome data were collected at more than one time point within the timeframe, as most studies reported data at 6-months, the data collection closest to this point was used (e.g., if 6 and 12 month post-baseline data were available, 6 month data were entered into the metaanalysis). The Higgin's statistic $\left(\mathrm{I}^{2}\right)$ was calculated to measure the heterogeneity across studies and interpreted as $0 \%$ indicating no heterogeneity, $25 \%$ low, $50 \%$ moderate, and $>75 \%$ high heterogeneity [71]. It was anticipated that there would be considerable heterogeneity across studies arising from differences in the interventions delivered, sample characteristics, and study designs. As such, a random effects model was used for meta-analysis calculations. As the number of studies was small, in addition to the DerSimonian-Laird approach, the Knapp-Hartung approach was used to make small-sample adjustments to the variance estimates of any outcomes that were statistically significant [75]. This more conservative approach produces a wider confidence limit appropriate when the sample size is small [75]. All tests were two-sided, and the significance level was set at $p<0.05$. These analyses were conducted using RevMan 5.3.

Publication bias was evaluated through inspection of funnel plots of the primary outcome variable of depression [38]. The effect of potential moderators on the primary outcomes was also assessed [76]. The prespecified moderators, participant and intervention characteristics, are detailed in Table 1 . Studies were separated into sub-groups based on these variables and metaregressions were performed to identify whether there 
Table 1 Descriptive summary of included studies

\begin{tabular}{|c|c|c|}
\hline $\begin{array}{l}\text { Author, Year, Aim(s) } \\
\text { Country, } \\
\text { Quality } \\
\text { Assessment } \\
\text { Score (QAS) } \\
\text { (/17) }\end{array}$ & Demographics & $\begin{array}{l}\text { Intervention and control } \\
\text { conditions and assessments }\end{array}$ \\
\hline
\end{tabular}

\begin{tabular}{ll}
\hline Barley et al., & To explore the acceptability and \\
$2014[78,79]$ & feasibility of procedures to inform \\
United & a definitive RCT of a practice \\
Kingdom & nurse-led personalised care inter- \\
Pilot RCT (2 & vention for CHD patients with at \\
groups) & least probable depression and \\
QAS:11 & chest pain.
\end{tabular}

QAS:11

Symptomatic chronic heart
disease (with active chest
pain)
$N=81(T=41, C=40)$
Mean age: $65(S D=11)$
$\%$ female $=35.8$
Race/ethnicity: $83 \%$ white
Mean HADS-D score: $T=12$
$(S D=3), C=11(S D=3)$

Boele et al., $2018[80,81]$ Netherlands RCT (3 groups) QAS: 10
To decrease depressive symptoms using low-intensity guided selfhelp based on problem-solving therapy delivered online to increase accessibility and decrease barriers to accessing mental health care.

\section{Glioma (CNS cancer)} $N=115(T=45, C 1=26, C 2=44)$ Mean age: $\mathrm{T}=43.6(\mathrm{SD}=11.7)$ $\mathrm{C} 1=52.8(\mathrm{SD}=9.3), \mathrm{C} 2=46.4$ $(\mathrm{SD}=12.3)$

$\%$ female: $\mathrm{T}=57.8, \mathrm{C} 1=65.4$, C2 $=59.1$

Most common diagnosis in $\mathrm{C} 1$ : non-Hodgkin lymphoma (46.2\%) Mean CES-D score: $T=21.5(\mathrm{SD}=$ 6.1), $\mathrm{C} 1=25.1(\mathrm{SD}=6.7), \mathrm{C} 2=$ $24.1(\mathrm{SD}=6.6)$

dialysis)

$N=55(T=27, C=28)$

Mean age: $T=49.1(S D=14.5)$,

$C=52.3(\mathrm{SD}=15.6)$

$\%$ female: $T=52, C=50$

Mean HADS-D: $T=10.2(\mathrm{SD}=$

3.4), $C=10.1(S D=3.4)$

\begin{abstract}
T: Nine sessions (one face-toface assessment + 15-min follow up phone calls) with nurse focused on identifying problems contributing to depression, providing support resources, devising personal health plan, goal setting, and building self-efficacy. C: Usual care.
\end{abstract}

Format: Individual.

Mode of delivery: Face-to-face and telephone.

Interventionist: Nurse.

Intervention duration: Mean

203 min (SD 100) of nurse time (mean 78min SD 19 for face-toface assessment; mean $125 \mathrm{~min}$ SD 91 in follow-up telephone calls).

Intervention length: 6-months. Level of guidance: Guided Timing of measures: 1-, 6-, and

12-months post baseline.

$\mathbf{T}=$ Guided self-help course based on problem-solving therapy including disease specific information. Five modules and exercises. Online support and feedback on exercises provided by coach.

C1 = Non-CNS cancer control group. Received intervention. C2 = Glioma 12-week waitlist control group (WLC).

Format: Individual.

Mode of delivery: Online Interventionist: Psychologist, nurse, or psychology

student (coaches)

Intervention duration: $\mathrm{n} / \mathrm{a}$

Intervention length: 5 weeks. Level of guidance: Guided selfdirected.

Timing of measures: 1.5-, 3-,

12-months post-baseline (last outcome measure not included for analysis as WLC group had completed intervention).

T: Psychoeducational intervention ( 3 sessions $\times 60 \mathrm{~min}$ ) focused on disease-specific information (e.g., physiology, causes, treatments) as well as problemsolving, stress management adaptive responses, and muscle relaxation.

C: Usual care.

Format: Group

Mode of delivery: Face-to-face. Interventionist: Unspecified. In collaboration with a nephrologist and psychiatrist.

Intervention duration: $180 \mathrm{~min}$. Intervention length:

Approximately 5 days.
Outcome(s)

Primary $(P)$,

Secondary (S),

Unspecified (O)]

P: $\mathrm{T} 1$ = C for depression

$\mathrm{T} 2=\mathrm{C}$ depression

S: $\mathrm{T} 1=\mathrm{C}$ for anxiety

$\mathrm{T} 1=\mathrm{C}$ for MCS and PCS

$\mathrm{T} 2=\mathrm{C}$ for anxiety, MCS, and PCS
P: $\mathrm{T} 1=\mathrm{C} 2$ for depression

S: T1 > C2 for MCS (ES: 0.87)

$\mathrm{T} 1=\mathrm{C} 2$ for PCS
P: $\mathrm{T} 1$ = C for depression and anxiety 
Table 1 Descriptive summary of included studies (Continued)

\begin{tabular}{llll}
\hline Author, Year, Aim(s) & Demographics & $\begin{array}{l}\text { Intervention and control } \\
\text { conditions and assessments }\end{array}$ & $\begin{array}{l}\text { Outcome(s) } \\
\text { [Primary (P), } \\
\text { Country, }\end{array}$ \\
Quality & & & Secondary (S), \\
Assessment & & Unspecified (O)] \\
Score (QAS) & & \\
(/17) & &
\end{tabular}

Fischer et al., To evaluate the feasibility and 2015 [83] efficacy of a fully automated Germany internet-based CBT program to reRCT (2 duce depressive symptoms in pagroups) tients with multiple sclerosis (MS).
Lamers et al., To evaluate the effectiveness of a 2010a [84, 85] nurse-administered minimal psyNetherlands RCT (2 groups) QAS: 12 chological intervention in reducing depressive symptoms in elderly primary care patients with type II diabetes or COPD with co-morbid non-severe depression and examine whether type of chronic illness modified the effects of the intervention.

\section{Multiple sclerosis} $N=90(T=45, C=45)$

Mean age: $\mathrm{T}=45.4(\mathrm{SD}=12.6)$,

$C=4524(S D=10.6)$

\% female: $T=76, C=80$

Mean BDI score: $\mathrm{T}=19.4(\mathrm{SD}=$

9.0), $C=18.4(S D=8.2)$
Type II diabetes, COPD $N=361(T=183, C=178)$

Mean age: $T=70.8(S D=6.5)$, $\mathrm{C}=70.6(\mathrm{SD}=6.8)$

\% female: $T=46.4, C=46.6$

Primary diagnosis:

T: $49.7 \%$ diabetes, $50.3 \%$ COPD

C: $52.8 \%$ diabetes, $47.2 \%$ COPD Mean BDI score:

$\mathrm{T}=17.1(\mathrm{SD}=7.2)$

$\mathrm{C}=17.7(\mathrm{SD}=8.0)$
To evaluate the effect of a nurseadministered minimal psychological intervention on disease specific quality of life, depression, and anxiety in elderly primary care patients with COPD with comorbid non-severe depression.

\section{COPD}

$N=187(T=96, C=91)$

Mean age: $T=70.5(S D=6.3)$,

$\mathrm{C}=71.5(\mathrm{SD}=7.1)$

$\%$ female: $\mathrm{T}=38.5, \mathrm{C}=41.8$

Mean BDI score:

$\mathrm{T}=17.1(\mathrm{SD}=6.5), \mathrm{C}=18.3(\mathrm{SD}=$
Level of guidance: Guided. Timing of measures: 1-month post-baseline.

$\mathbf{T}=$ Ten online modules using simulated dialogue and tailored based on participant response. Content draws on: 1) behavioral activation, 2) cognitive modification, 3) mindfulness and acceptance, 4) interpersonal skills, 5) relaxation, physical exercise and lifestyle modification, 6) problem solving, 7) childhood experiences and early schemas, 8) positive psychology interventions, 9) dreamwork and emotionfocused interventions, and 10) psychoeducation. C=2.25-month WLC

Format: Individual.

Mode of delivery: Online. Interventionist: Self-directed. Intervention duration: Selfdirected. Mean use: $332 \mathrm{~min}$ (range 50-905 min).

Length of intervention: 2.25 months.

Level of guidance: Self-directed. Timing of measures: 2.25 - and 8.25-months post-baseline (last outcome measure not included for analysis as WLC group had completed intervention).

$\mathbf{T}=$ Tailored intervention with variable number of sessions (210) based on principles of selfmanagement and CBT and includes 5 phases: 1) exploring feelings, cognitions, and behaviours, 2) mood, symptom, and behaviourmonitoring, 3) linking mood to behaviour, 4) action planning, and 5) evaluation of progress in achieving goals. C= Usual care.

Format: Individual.

Mode of delivery: Face-to-face. Interventionist: Nurse.

Intervention duration: Mean 240 min.

Intervention length: Tailored up to 3-months.

Level of guidance: Guided.

Timing of measures:

Approximately 3.25-, 6-, and 12months post-baseline (assuming 3-month intervention period).

See Lamers et al., 2010a

P: $\mathrm{T} 1=\mathrm{C}$ for depression* T2 = C for depression* (Note: $\mathrm{T}>\mathrm{C}$ for depression at 9-months post intervention completion).* S: $\mathrm{T} 1=\mathrm{C}$ for anxiety* $\mathrm{T} 2=\mathrm{C}$ for anxiety* (Note: $\mathrm{T}>\mathrm{C}$ for anxiety at 9-months post intervention
P: $\mathrm{T} 1$ = C for depression S: $T=C$ for fatigue
P: $\mathrm{T} 1$ = C for depression

$\mathrm{T} 2=\mathrm{C}$ for depression

S: $\mathrm{T} 1=\mathrm{C}$ for MCS and PCS

Tor MCS and PCS

COPD sub-group*

$\mathrm{T} 2=\mathrm{C}$ for MCS

DMII sub-group*

$\mathrm{T} 1=\mathrm{C}$ for MCS

$2=C$ for MCS (note: $T>C$ for

MCS at 9-months post intervention completion)* 
Table 1 Descriptive summary of included studies (Continued)

\begin{tabular}{lll}
\hline Author, Year, Aim(s) & Demographics & $\begin{array}{l}\text { Intervention and control } \\
\text { country, }\end{array}$ \\
Quality & & \\
Assessment & & \\
Score (QAS) & & \\
(/17) & & \\
\hline RCT $(2$ &
\end{tabular}

\section{$\mathrm{RCT}(2$}

groups)

Lamers et al., 2011 [87]

Note:

Subgroup analysis of Lamers 2010a Netherlands $\mathrm{RCT}(2$ groups)

Lee et al., 2014 [88] Republic of Korea

Quasi-RCT group allocation based on consent date (2 groups) QAS: 12
To evaluate whether a nurseadministered minimal psychological intervention based on CBT and self-management principles improves disease-specific quality of life and glycemic control in patients with type II diabetes and comorbid non-severe depression.
7.2)

\section{Type II diabetes}

$N=208(T=105, C=103)$ Mean age: $T=70.7(\mathrm{SD}=6.6)$ $C=69.7(S D=6.6)$ $\%$ female: $\mathrm{T}=51.4, \mathrm{C}=50.4$ Depression level: Not specified. Participants underwent Mini International Neuropsychiatric review. Those with minor depression, mild-to-moderate major depression or dysthymia were included.

Type II diabetes

* per group data not available $N=36(T=19, C=17)$ Median age: 57.5 (range 34-71) \% female: 55.6 Mean HADS-D score: $\mathrm{T}=12.0(\mathrm{SD}=3.7), \mathrm{C}=12.7(\mathrm{SD}=$ 1.5 cer patients reporting significant levels of distress.
See Lamers et al, 2010a

\section{$\mathbf{T}=$ Twenty-minute} psychoeducation video clip. Content consisted of distress education, cancer survivor interview, coping strategies and stress management,

and psychological services.

$\mathbf{C}=$ Control movie clip of scenic images and relaxing music.

Format: Individual.

Mode of delivery: Video presented on computer tablet. Interventionist: $\mathrm{n} / \mathrm{a}$

Intervention duration: $20-\mathrm{min}$ Length of intervention: 20-min. Level of guidance: Self-directed Timing of measures: 1-day (post-intervention same day as baseline measures) and 2-4 weeks post-baseline.

T: Structured lifestyle intervention (17 sessions $\times 1.5-2$ h). Two individual sessions

followed by two weekly, four biweekly, and nine monthly group sessions. Intervention compo-

nents focused on diet and physical activity, including a weight loss, exercise, and caloric intake goals, combined with cognitive behavioural and social learning approaches to managing depression.

C: Usual care + brief educational booklet on diabetes

management.

Format: Individual and group.

Mode of delivery: Face-to-face. Interventionist: Therapists. Intervention duration: 1530 to 2040 min.

Intervention length: 12-months. Level of guidance: Guided.

Timing of measures: 6 - and 12months post-baseline.

$\mathbf{T}=$ Sessions [(8 weekly sessions +2 booster sessions) $\times 1 \mathrm{~h} /$ session] focused on recognizing signs and symptoms of depression, relationship between
Outcome(s)

Primary (P),

Secondary (S),

Unspecified (O)]

completion)*

S: $\mathrm{T} 1=\mathrm{C}$ for glycemic control (HbA1c)

$\mathrm{T} 2=\mathrm{C}$ for glycemic control (HbA1c)
P: T1 > C for depression (ES: 1.13) and MCS (ES: 1.08)

$\mathrm{T} 1=\mathrm{C}$ for anxiety
P: T2 > C for depression (ES: $0.62)$

$2=\mathrm{C}$ for glycemic control (HbA1c)
Penckofer et al., 2012 [90] United States RCT (2
To examine the effects of a nursevention on depression, anxiety, and anger among women with type II diabetes.
Type II diabetes

$N=74(T=38, C=36)$

$\mathrm{C}=54.0(\mathrm{SD}=8.4)$

$\%$ female: 100
P: T1 > C for depression (ES: $0.78)$

$\mathrm{T} 1=\mathrm{C}$ for trait anxiety

$\mathrm{T} 1=\mathrm{C}$ for state anxiety

T2 > C for depression (ES: - 0.94) 
Table 1 Descriptive summary of included studies (Continued)

\begin{tabular}{|c|c|c|}
\hline $\begin{array}{l}\text { Author, Year, Aim(s) } \\
\text { Country, } \\
\text { Quality } \\
\text { Assessment } \\
\text { Score (QAS) } \\
\text { (/17) }\end{array}$ & Demographics & $\begin{array}{l}\text { Intervention and control } \\
\text { conditions and assessments }\end{array}$ \\
\hline $\begin{array}{l}\text { groups) } \\
\text { QAS: } 12\end{array}$ & $\begin{array}{l}\text { Mean CES-D score: } T=27.7(S D= \\
9.3) \\
C=28.9(S D=9.5)\end{array}$ & $\begin{array}{l}\text { mood, metabolic control, and } \\
\text { self-care behaviours, the man- } \\
\text { agement of depression, anxiety, } \\
\text { and anger using CBT. Includes el- } \\
\text { ements from existing interven- } \\
\text { tions such as CBT program for } \\
\text { depression, progressive muscle } \\
\text { relaxation CD, and system for } \\
\text { management of anger including } \\
\text { workbook and video. } \\
\text { C= Usual care. } \\
\text { Format: Group. } \\
\text { Mode of delivery: Face-to-face. } \\
\text { Interventionist: Nurse. } \\
\text { Intervention duration: } 600 \text { min } \\
\text { Intervention length: 6-months } \\
\text { Level of guidance: Guided. } \\
\text { Timing of measures: 3- and 6- } \\
\text { months post-baseline. }\end{array}$ \\
\hline
\end{tabular}

Rees et al., To provide preliminary evidence 2017 [91] for the impact of problem-solving Australia therapy for diabetes in adults with Pilot RCT (2 diabetic retinopathy and diabetes groups) distress.

QAS: 13

Schroder

et al., 2014

[92]

Germany

RCT (2

groups)

QAS: 10
Type II diabetes and diabetic retinopathy

$N=40(T=21, C=19)$

Mean age: $T=60.1(S D=7.0)$,

$\mathrm{C}=59.6(\mathrm{SD}=8.8)$

\% female: $T=33.3, C=31.6$

Mean PHQ-9 score: $\mathrm{T}=10.5$

$(\mathrm{SD}=5.2)$

$C=10.2(S D=5.7)$
To evaluate the feasibility and efficacy of an online program for depression in individuals with epilepsy and co-morbid depressive symptoms.
Epilepsy

$N=78(T=38, C=40)$ Mean age: $T=35.0(S D=10.0)$,

$\mathrm{C}=40.0(\mathrm{SD}=11.9)$

$\%$ female: $T=67.5, C=84.2$

Mean BDI score:

$\mathrm{T}=22.2(\mathrm{SD}=10.4)$

$C=19.4(S D=9.8)$
T: Provided publicly available information on diabetes + problem solving therapy for diabetes, which consisted of weekly sessions $(8 \times 45-60 \mathrm{~min})$ in which participants identified problems related to diabetes and were guided through a problemsolving process. Participants were also asked to make plans to engage in enjoyable activities. C: Usual care + same publicly available brochures on diabetes as $T$ group.

Format: Individual

Mode of delivery: Phone or inperson (based on preference and availability).

Interventionist: Research assistant supervised by clinical psychologist.

Intervention duration: 360 $480 \mathrm{~min}$.

Intervention length: 2-months Level of guidance: Guided. Timing of measures: 3 - and 6months post-baseline.

T: Ten online modules (10-60 min each) comprised mostly of CBT elements (cognitive restructuring, behavioural activation) and mindfulness and acceptance exercises.

C: 9-week WLC

Format: Individual

Mode of delivery: Online.

Interventionist: Self-directed.

Intervention duration: 100-

600 min.

Intervention length: 2.25

months.

Level of guidance: Self-directed.

Timing of measures: 2.25

months post-baseline.

$\mathbf{T}$ : The intervention consisted of up to 10 weekly problem-solving
Outcome(s)

Primary $(\mathrm{P})$

Secondary (S),

Unspecified (0)]

and trait anxiety (ES: -0.62$)$

$\mathrm{T} 2=\mathrm{C}$ for state anxiety (ES: $0.74)$

S: $\mathrm{T} 1=\mathrm{C}$ for MCS

$\mathrm{PCS}$, and

glycemic control (HbA1c)

$\mathrm{T} 2=\mathrm{C}$ for PCS and glycemic control (HbA1c)

T2 > C for MCS (ES: 0.60)

S: $\mathrm{T} 1=\mathrm{C}$ for depression and glycemic control (HbA1c) $\mathrm{T} 2=\mathrm{C}$ for depression and glycemic control (HbA1c)
P: $\mathrm{T} 1=\mathrm{C}$ for depression
Sharpe et al., To perform preliminary evaluation 2004 [93] of the feasibility and efficacy of a
Cancer (outpatients with breast, gynaecological, bladder,
P: $\mathrm{T1}>$ C for depression (ES: $0.87)$ 
Table 1 Descriptive summary of included studies (Continued)

\begin{tabular}{|c|c|c|}
\hline $\begin{array}{l}\text { Author, Year, } \\
\text { Country, } \\
\text { Quality } \\
\text { Assessment } \\
\text { Score (QAS) } \\
\text { (/17) }\end{array}$ & $\operatorname{Aim}(s)$ & Demographics \\
\hline $\begin{array}{l}\text { United } \\
\text { Kingdom } \\
\text { (Scotland) } \\
\text { Non- } \\
\text { randomized } \\
\text { matched } \\
\text { control group } \\
\text { design (2 } \\
\text { groups) }\end{array}$ & $\begin{array}{l}\text { nurse-led intervention with oncol- } \\
\text { ogy outpatients. }\end{array}$ & $\begin{array}{l}\text { prostate, testicular and } \\
\text { colorectal) } \\
N=60(T=30, C=30) \\
\text { Mean age: } T=58.0(S D=10.6), \\
C=56.0(S D=10.5) \\
\% \text { female: } T=93.3, C=93.3 \\
\text { Mean HADS-D score: } \\
T=10.4(S D=3.6) \\
C=10.3(S D=4.0)\end{array}$ \\
\hline
\end{tabular}

$\begin{array}{ll}\text { Intervention and control } & \text { Outcome(s) } \\ \text { conditions and assessments } & \text { [Primary (P), } \\ & \text { Secondary (S), } \\ & \text { Unspecified (O)] }\end{array}$

therapy sessions (30 min each) to T2 >C for depression (ES: - 0.58) help with a positive and system- $\quad \mathbf{S}: \mathrm{T1}>\mathrm{C}$ for anxiety (ES: -1.25$)$ atic approach to tackling prob- $\quad$ T2 $>$ C for anxiety (ES: -0.88 ) lems, education about depression, encouragement to speak with their general practitioner about anti-depressant medication, and coordination and monitoring of the participant's depression treatment. Participants could contact the nurse for further booster sessions.

C: Usual care.

Format: Individual.

Mode of delivery: Face-to-face or phone.

Interventionist: Nurse

supervised by psychiatrist.

Intervention duration: Nurse

spent mean of 360 min with

participants.

Intervention length: Ranged

from 0.5-4 months (with 6

participants requesting booster sessions).

Level of guidance: Guided.

Timing of measures: $3-$ and 6months post-baseline.

T: Based on Strong et al. (2008). Primary care physician and oncologist informed of major depression disorder diagnosis + multicomponent treatment program integrated into cancer care in which participants form relationships with nurses who provide information about depression, deliver problemsolving therapy, and monitor progress (up to 10 sessions $X 45$ min and additional sessions available for those not meeting treatment targets).

C: Usual care + primary care physician and oncologist informed of major depression diagnosis + participant encouraged to consult their primary care physician to obtain treatment.

Format: Individual.

Mode of delivery: Primarily

face-to-face, sometimes telephone.

Interventionist: Oncology

nurses supervised by a

psychiatrist.

Intervention duration: $405 \mathrm{~min}$. Median number of sessions: 9 (range 0-10).

Intervention length: 4-months for initial sessions and further sessions for those who are not meeting treatment targets.

Level of guidance: Guided. Timing of measures: 3-, 6-, 9-, and 12-months post-baseline.
P: T1 > C for depression (ES: $0.87)$

T2 > C for depression (ES: -1.03 )

S: T1 > C for anxiety (ES: -0.61$)$ and fatigue (ES: - 0.41)

T2 >C for anxiety (ES: - 0.71) and fatigue (ES: -0.60$)$ 
Table 1 Descriptive summary of included studies (Continued)

\begin{tabular}{lll}
\hline Author, Year, Aim(s) & Demographics & $\begin{array}{l}\text { Intervention and control } \\
\text { Country, }\end{array}$ \\
Quality & & \\
Assessment & & \\
Score (QAS) & & \\
(/17) &
\end{tabular}

\begin{tabular}{lll}
\hline Strong et al., & To assess the efficacy and cost of & Cancer \\
2008 [95] & a nurse-delivered complex inter- & $N=200(T=101, C=99)$ \\
(SMaRT & vention designed to treat major & Mean age: $T=56.6(S D=11.4)$, \\
oncology 1) & depressive disorder in patients & $C=56.6(S D=12.3)$ \\
United & with cancer. & $\%$ female: $T=69, C=72$ \\
Kingdom & & Median SCL-20 score (IQR): $T=$ \\
(Scotland) & & $2.35(2.05-2.75), C=2.25(1.95-$ \\
RCT (2 & & $2.75)$
\end{tabular}

\begin{abstract}
T: Maximum of 10 session (45min each) over 3-months

followed by monthly monitoring of symptoms in the next $3-$ months and. optional 1-2 sessions for those whose depression scores increased. The intervention included education about depression and treatment, problem-solving treatment, and communicating with the participant's primary care physician and oncologist about their depression diagnosis.

C: Usual care + informed primary care physician and oncologist of depression diagnosis and, if requested, provided advice regarding choice of antidepressant medication.
\end{abstract}

Format: Individual.

Mode of delivery: Primarily inperson, some by telephone if needed.

Interventionist: Oncology nurse supervised by a psychiatrist. Intervention duration: Mean of $315 \mathrm{~min}$ based on mean of 7 sessions (range 2-10).

Intervention length: 6-months.

Level of guidance: Guided.

Timing of measures: 3-, 6-, and

12-months post-baseline

Thorton et al., To test experimentally whether a 2009 [96] United States RCT (2 groups) Secondary analysis QAS: 11 psychological intervention reduces depression-related symptoms and markers of inflammation among cancer patients. Mean CES-D lowa short-form
Breast cancer (Stage $\|/\| I \|$, surgically treated, and waiting for adjuvant therapies) $N=45(T=23, C=22)$ Mean age: $T=50.0(S D=8.6)$ $\mathrm{C}=50.0(\mathrm{SD}=11.6)$ $\%$ female: 100 score not reported. All participants included in the secondary analysis scored $\geq 10$ as part of inclusion criteria.
T: Group sessions of 8-12 patients for 90 min for 18 weekly sessions followed by 8 monthly sessions. Topics included stress management, emotional distress, social adjustment, health behaviours (e.g., diet, exercise), and adherence to treatment. C: Usual care.

\section{Format: Group}

Mode of delivery: Face-to-face (some telephone contact to catch up on information if sessions were missed).

Interventionist: Psychologists. Intervention duration: 2340 $\min$.

Intervention length: 12-months. Level of guidance: Guided. Timing of measures: 4-, 8-, $12-$ months post-baseline.

T: Adapted from Sharpe et al. (2014). Maximum of 10 sessions (30-45 min) over 4-months followed by monitoring of symptoms and optional additional sessions for participants who not meet treatment target. Nurses establish therapeutic relationship, provide information about depression, delivey
Outcome(s)

[Primary (P),

Secondary (S),

Unspecified (O)]

P: $\mathrm{T} 1>\mathrm{C}$ for depression*

T2 >C for depression*

S: T1 > C for anxiety and fatigue* T2 > C for anxiety and fatigue*
Walker et al., To assess the efficacy of an

(SMaRT

Oncology-3)

United

Kingdom

(Scotland)

RCT (2

groups)

QAS: 13
Lung cancer

$N=142(T=68, C=74)$

Mean age: $T=63.6$
$C=63.9(S D=8.7)$

$\%$ female: $\mathrm{T}=65, \mathrm{C}=65$

Mean SCL-20 score: $\mathrm{T}=1.90$ (SD

$0.52), C=1.98(0.58)$
P: T1 > C for depression*

T2 >C for depression* S: T1 $>$ C for fatigue* T2 > C for fatigue*
Outcomes averaged over the participants time in the trial (up to 8-months).

P: $T>C$ for depression*

S: T > C for anxiety*

$\mathrm{T}=\mathrm{C}$ for fatigue* 
Table 1 Descriptive summary of included studies (Continued)

\begin{tabular}{|c|c|c|c|}
\hline $\begin{array}{l}\text { Author, Year, Aim(s) } \\
\text { Country, } \\
\text { Quality } \\
\text { Assessment } \\
\text { Score (QAS) } \\
\text { (/17) }\end{array}$ & Demographics & $\begin{array}{l}\text { Intervention and control } \\
\text { conditions and assessments }\end{array}$ & $\begin{array}{l}\text { Outcome(s) } \\
\text { [Primary (P), } \\
\text { Secondary (S), } \\
\text { Unspecified (O)] }\end{array}$ \\
\hline
\end{tabular}

problem-solving therapy and be-
havioural activation and monitor
progress. Psychiatrists supervise
treatment, advise primary care
physicians, and provide direct
consultation to participants not
progressing.
C: Usual care + primary care
physician and oncologist
informed of the diagnosis of
major depression and participant
encouraged to see primary care
physician to obtain treatment.
Format: Individual.
Mode of delivery: Primarily
face-to-face, some telephone
contact.
Interventionist: Nurse and
psychiatrist.
Intervention duration: $240-$
360 min (median number of
sessions 8 IQR 7-10).
Intervention length: 8-months.
Level of guidance: Guided.
Timing of measures: 1-, 2-, 3-,
$4-, 5-, 6-, 7-$, and 8-months post-
baseline. Outcomes averaged
over the participants time in the
trial (up to 8-months).

Notes: Only post-intervention primary and secondary outcomes of interest in this review reported across at least 3 studies within one time period (T1 and/or T2) included. T1- baseline to $<6$ months post-baseline; $\mathrm{T} 2 \geq 6$ months post-baseline. $\mathrm{T}=$ treatment condition; $\mathrm{C}=$ control condition; $\mathrm{T}>\mathrm{C}=$ treatment significantly superior to control; $T<C=$ control superior to treatment; $T=C=$ no significant differences between. $E S=E f f e c t$ size (Hedge's $g$ calculated at 95\% confidence level); Intervention duration = number of minutes spent participating in intervention based on reported participation or expected duration; Intervention length= length of time over which intervention was delivered; *Indicates that insufficient data available to calculate effect size so outcome is as reported by authors; sign of effect size based on negative orientation of scale (as intervention always compared with control - scales in which decreased scores indicate improvement are negative); Duration of the intervention based on reported mean or median adherence (in minutes) multiplied by the number of sessions, or, if not available, amount of time authors reported intervention would take (e.g., 4 sessions $X 60 \mathrm{~min}=240 \mathrm{~min}$ ). If the range of individual sessions was provided (e.g., 15 to $30 \mathrm{~min}$ per session), the midpoint (e.g., 22.5) was multiplied by the number of sessions.; IQR interquartile range; CHD coronary heart disease, CNS central nervous system, PST problem-solving therapy; WLC wait list control group; MS multiple sclerosis; COPD chronic obstructive pulmonary disorder; $E R$ emergency room; QoL quality of life; $C B T$ cognitive behavioural therapy; BDI Beck Depression Inventory [40]; BDI-II Beck Depression Inventory-II [42]; CES-D Centre for Epidemiological Studies-Depression [44]; HADS-D Hospital Anxiety and Depression Scale-Depression [48]; PHQ-9 Patient Health Questionnaire [49]; HRQoL Health related Quality of Life and includes: PCS physical health composite scale; MCS mental health composite scale

was a statistically significant difference in outcomes between the sub-groups. There is no consensus on the number of studies required to run a meta-regression; these were performed when sub-groups included 4 or more studies ( $p$-value $<0.05$ was set to establish significance) [77]. As meta-regressions cannot be performed using the Revman 5.3 software, these were calculated using the 'metareg' program in STATA (version 15.1). If needed information for any of the above calculations was not reported in the publication, authors were contacted for further details. If data required for inclusion in the meta-analysis were not available, the study was included for descriptive review only. Due to the substantial diversity in reported outcomes, only outcomes reported at least three times at one time point (T1 or T2) were included for review.

\section{Results \\ Study selection}

In total, 21,663 titles were retrieved through database searches and over 500 titles were screened through secondary searches. After removing duplicates, 19,788 titles remained. Screening of these resulted in the inclusion of 2212 abstracts, 1832 of which were excluded, leaving 380 full texts to be reviewed. Seventeen manuscripts reporting on 15 studies were retained: 12 for inclusion in the metaanalysis and three for descriptive review only. Flow of studies and reasons for exclusion are detailed in Fig. 1. 

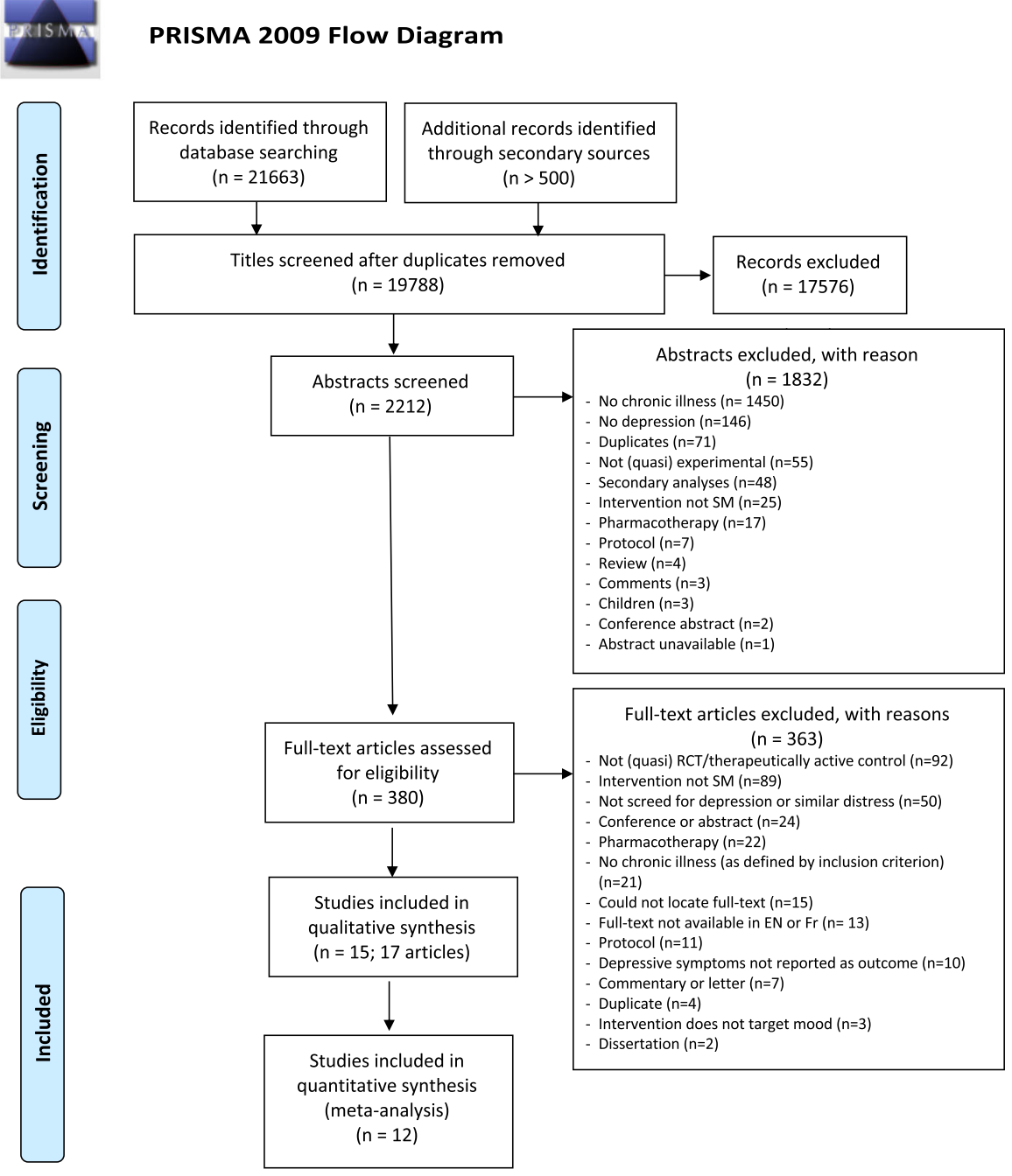

Full-text articles excluded, with reasons $\quad(n=363)$

Not (quasi) RCT/therapeutically active control $(n=92)$ Intervention not SM ( $n=89)$

Not screed for depression or similar distress $(n=50)$ Conference or abstract $(n=24)$

Pharmacotherapy $(n=22)$

No chronic illness (as defined by inclusion criterion)

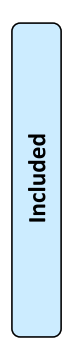

$(\mathrm{n}=21)$

Could not locate full-text ( $n=15$ )

Full-text not available in $\mathrm{EN}$ or $\mathrm{Fr}(\mathrm{n}=13)$

Protocol $(n=11)$

Depressive symptoms not reported as outcome $(n=10)$

Commentary or letter $(n=7)$

Duplicate $(n=4)$

Intervention does not target mood $(n=3)$

Dissertation $(n=2)$

Fig. 1 PRISMA 2009 Flow Diagram

\section{Description of studies}

Characteristics of included studies are described in Table 2 and there was no indication of publication bias (Appendix C). Studies were conducted in the United Kingdom $(n=5)$, United States $(n=3)$, the Netherlands $(n=2)$, Germany $(n=$ $2)$, Iran $(n=1)$, Republic of Korea $(n=1)$, and Australia $(n=$ $1)$. Eleven studies used a 2-group RCT design (including two pilot trials), two studies used a 2-group quasi-experimental design, and one used a 3-group RCT design. The intervention groups were compared to usual care $(n=6)$, attention control groups $(n=6)$ (e.g., provided publicly available health information), or waitlist control $(n=3)$.

\section{Participants}

In total, 2064 participants were included in this review, with study sample sizes ranging from 40 [91] to 500 [94]. Most studies $(n=12)$ included more women than men and two studies included only women $[90,96]$. Participants' primary diagnoses were cancer $(n=7)[80,89$, 93-97], diabetes type II $(n=4)$ [84, 88, 90, 91], chronic heart disease $(n=1)$ [78], chronic obstructive pulmonary disorder $(n=1)$ [84], multiple sclerosis (MS) $(n=1)$ [83], epilepsy $(n=1)$ [92], and chronic kidney disease $(n=1)$ [82] (non-exclusive categories as some studies focused on two disease groups). Mean reported age in the 
Table 2 Effect sizes for T1 and T2 for secondary outcomes

\begin{tabular}{|c|c|c|c|c|c|c|}
\hline \multirow[b]{3}{*}{ Secondary Outcomes } & \multicolumn{6}{|l|}{ Timepoints } \\
\hline & \multicolumn{3}{|l|}{$\mathrm{T1}$} & \multicolumn{3}{|l|}{$\mathrm{T} 2$} \\
\hline & \# of studies & SMD (95\% Cl) & $1^{2}(\%)$ & \# of studies & SMD $(95 \% \mathrm{Cl})$ & $I^{2}(\%)$ \\
\hline Anxiety & 7 & $-0.42[-0.73,-0.12]$ & 73 & 4 & $-0.52[-0.94,-0.10]$ & 77 \\
\hline Mental Component Score (HRQoL) & 5 & $0.43[0.09,0.76]$ & 60 & 3 & $0.12[-0.28,0.53]$ & 67 \\
\hline Physical Component Score (HRQoL) & 5 & $0.01[-0.18,0.20]$ & 0 & 3 & $0.03[-0.18,0.24]$ & 0 \\
\hline Fatigue & 3 & $-0.36[-0.67,-0.06]$ & 50 & 1 & $-0.60[-0.78,-0.41]$ & \\
\hline Glycemic Control (HbA1c) & 3 & $-0.08[-0.57,0.41]$ & 49 & 4 & $-0.35[-0.62,-0.07]$ & 0 \\
\hline
\end{tabular}

Note: T1 baseline to < 6-months; T2 $\geq 6$-months. HRQoL Health-related Quality of Life, $I^{2}$ Higgin's $\left.\right|^{2}$ statistic, $\mathrm{Cl}$ confidence interval

sample ranged from 35.0 to 70.8 years. Depressive symptomatology across study groups ranged from mild to severe, with the mean reported symptoms most often in the moderate range [41-44, 47-49, 98, 99].

\section{Interventions}

Included interventions are described in Table 2. Six of the 15 studies evaluated the same or similar interventions in different populations (4 one type of intervention and 2 another) $[83,92-95,97]$. Time spent participating in interventions (duration) ranged from 20 [88] to $2340 \mathrm{~min}$ [96] $(n=14$, mean $=552.9, \mathrm{SD}=662.9)$. The length of time over which interventions were delivered ranged from one session [88] to two 12 month programs $[89,96]$.

The primary format of the interventions was individual $(n=11)$ [78, 80, 83, 84, 88, 91-95, 97]; however, three studies used a group format $[82,90,96]$, and one included both group and individual sessions [89]. In terms of mode of delivery, seven studies used a combination of face-toface and telephone contact (most favoured face-to-face contact with telephone follow-up only if needed) [78, 91, 93-97], four were delivered entirely face-to-face [82, 84, $89,90]$, three were online $[80,83,92]$, and one was a video on a computer tablet [88].

In terms of level of guidance, most were led by an interventionist $(n=11)$ [78, 82, 84, 89-91, 93-97], three were self-directed (two online programs and one video) [83, 88, 92], and one intervention was guided self-directed (participants independently worked through the intervention with feedback on exercises) [80]. The interventionists were all HCPs, other than one provided by a trained research assistant supervised by a psychologist [91]. Four of the interventions were delivered by nurses supervised or supported by psychiatrists [93-95, 97], three were delivered solely by nurses [78, 84, 90], one by psychologists [96], and the remaining two interventions were delivered by interdisciplinary HCPs [80, 82].
The content of the interventions focused on a combination of structured problem-solving $(n=12)$ [78, 80, 84, 89, 91-97], providing disease specific health information $(n=13$; it was an optional component in two of the 13 interventions) [78, 82, 88-97], relaxation and stress management $(n=7)$ [82, 83, 88-90, 92, 96], using CBT principles (e.g., challenging negative self-talk) $(n=5)$ [83, 84, 89, 90, 92], care coordination (e.g., communicating the depressive symptoms to HCP team members) $(n=4)$ [93-95, 97], and finding health services $(n=2)[78,88]$.

Eleven interventions were coded for a possible 13 depression self-management skills (interventions that contained the same content were combined). The skills identified for each intervention are summarized in Appendix A. Across the sample, the mean number of skills was $6.2(\mathrm{SD}=2.4$, range $2-11)$. The most frequently included skill was problem-solving $(n=9)$, followed by decision-making $(n=8)$, taking action $(n=7)$, social support $(n=7)$, and self-tailoring $(n=7)$. Less frequently addressed skills were social support $(n=1)$, resource utilization $(n=2)$, and forming partnerships with HCPs $(n=2)$.

\section{Methodological quality}

Quality assessment scores are included in Table 2 and detailed scoring is available in Appendix D. The mean quality assessment score across the sample was 11.2 (SD 2.14) out of a possible 17 indicating that on average the studies were of moderate methodological quality. Scores ranged from 6 to 14 with four studies assessed as being of high methodological quality [91, 94, 95, 97]. The least met criteria related to blinding.

\section{Outcomes: Descriptive and meta-analysis Primary outcome: Depression}

Eleven studies were included in the meta-analysis for the T1 period (see Fig. 2). The pooled effect size of -0.47 [95\% CI $-0.73,-0.21]$ was significant with high heterogeneity $\mathrm{I}^{2}=76 \%$ and favoured the interventions over the control conditions. The results remained significant after 


\section{Forest Plot of Depression T1 - Baseline to $<6$ months}

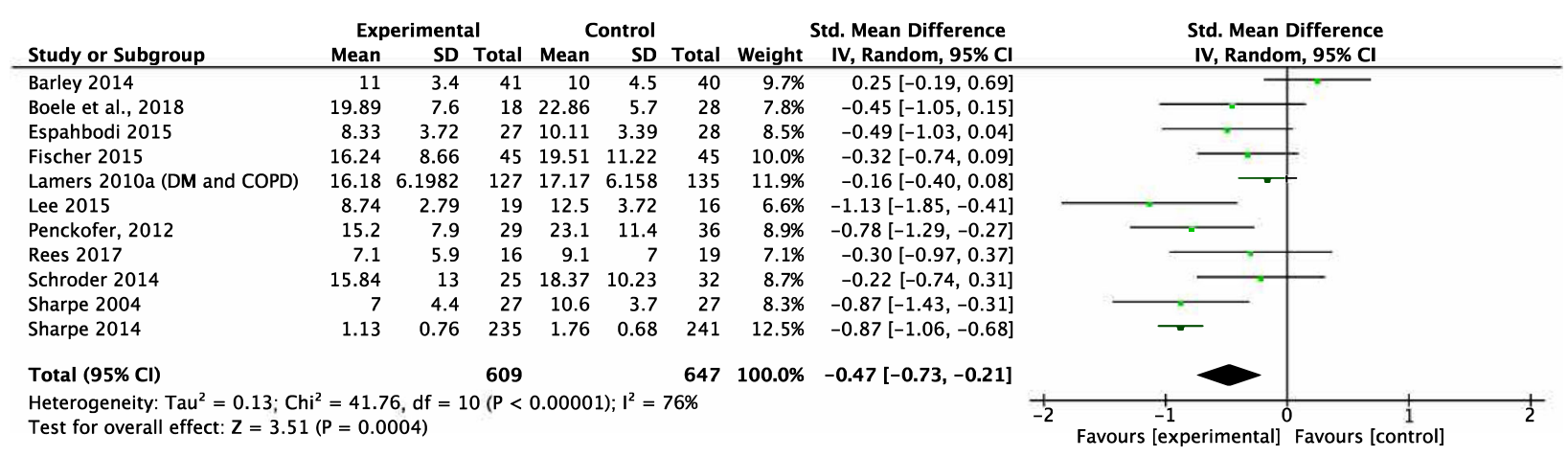

Fig. 2 Forest Plot of Depression T1 - Baseline to $<6$ months

the Knapp-Hartung (KH) conversion [95\% CI -0.74, $0.02]$. Statistically significant effect sizes ranged from 0.78 [90] to -1.13 [88].

When examining potential sources of heterogeneity, three studies reported pharmacological co-intervention that was significantly imbalanced between the intervention and control groups (participants in the intervention group were more likely to begin pharmacotherapy than those in the control group) [78, 93, 94]. When these studies were removed from the meta-analysis, the pooled effect size with 8 studies was of -0.41 [95\% CI $-0.61,-0.20]$ with $\mathrm{I}^{2}=32 \%$. Using both the DerSimonian-Laird and the more conservative $\mathrm{KH}$ approach and examining potential sources of heterogeneity, the findings of all analyses indicated a statistically significant moderate effect of interventions as compared to control conditions. The two studies not included in the meta-analysis measuring depression outcomes reporting findings in line with those of the meta-analysis $[95,96]$.

In the T2 time period, 7 studies were included in the meta-analysis (see Fig. 3). The pooled effect size of -
0.53 [95\% CI $-0.91,-0.15]$ was statistically significant with high heterogeneity, $\mathrm{I}^{2}=86 \%$ favouring the interventions. The results remained significant after $\mathrm{KH}$ conversion $[95 \%$ CI $-95,-0.13]$. Excluding the same three studies as in $\mathrm{T} 1[78,93,94]$ from the meta-analysis resulted in a pooled effect size, with 4 studies, of -0.53 $[95 \%$ CI $-0.84,-0.21]$ with moderate heterogeneity, $\mathrm{I}^{2}=$ $50 \%$. The one study [97] not entered into the metaanalysis at $\mathrm{T} 2$ also favored the intervention over control group.

\section{Secondary outcomes}

A summary of results for secondary outcomes is presented in Table 3. Forest plots of meta-analysis results at the $\mathrm{T} 1$ and $\mathrm{T} 2$ periods for secondary outcomes are in Appendix E.

Anxiety. In the T1 period, 7 studies were entered in the meta-analysis $[78,82,86,88,90,93,94]$. The pooled effect size was -0.42 [95\% CI $-0.73,-0.12]$ with heterogeneity of $\mathrm{I}^{2}=73 \%$ in favour of the interventions. This finding remained significant after HK

\begin{tabular}{|c|c|c|c|c|c|c|c|c|c|c|c|c|}
\hline \multirow[b]{2}{*}{ Study or Subgroup } & \multicolumn{3}{|c|}{ Experimental } & \multicolumn{3}{|c|}{ Control } & \multicolumn{2}{|c|}{ Std. Mean Difference } & \multirow{2}{*}{\multicolumn{4}{|c|}{$\begin{array}{l}\text { Std. Mean Difference } \\
\text { IV, Random, } 95 \% \mathrm{Cl}\end{array}$}} \\
\hline & Mean & SD & Total & Mean & SD & Total & Weight & IV, Random, 95\% Cl & & & & \\
\hline Barley 2014 & 10.3 & 3.8 & 41 & 9.2 & 4.6 & 40 & $14.4 \%$ & $0.26[-0.18,0.70]$ & & 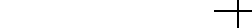 & 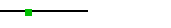 & \\
\hline Lamers 2010a (DM and COPD) & 15.88 & 6.3214 & 111 & 17.49 & 6.261 & 125 & $16.5 \%$ & $-0.26[-0.51,0.00]$ & & - & & \\
\hline Moncrief 2016 & 10.75 & 7.76 & 42 & 16.09 & 9.15 & 48 & $14.6 \%$ & $-0.62[-1.05,-0.20]$ & & & & \\
\hline Penckofer, 2012 & 12.6 & 8 & 26 & 21.5 & 10.2 & 34 & $13.1 \%$ & $-0.94[-1.48,-0.40]$ & & - & & \\
\hline Rees 2017 & 6.7 & 5.9 & 16 & 9.9 & 6.5 & 19 & $11.4 \%$ & $-0.50[-1.18,0.18]$ & & - & - & \\
\hline Sharpe 2004 & 7 & 4.1 & 26 & 9.6 & 4.7 & 26 & $12.9 \%$ & $-0.58[-1.14,-0.02]$ & & & & \\
\hline Sharpe 2014 & 0.96 & 0.72 & 231 & 1.72 & 0.75 & 231 & $17.1 \%$ & $-1.03[-1.23,-0.84]$ & & - - & & \\
\hline \multirow{2}{*}{\multicolumn{7}{|c|}{$\begin{array}{l}\text { Total }(95 \% \mathrm{Cl}) \\
\text { Heterogeneity: } \mathrm{Tau}^{2}=0.21 ; \mathrm{Chi}^{2}=41.91, \mathrm{df}=6(\mathrm{P}<0.00001) ; \mathrm{I}^{2}=86 \% \\
\text { Test for overall effect: } \mathrm{Z}=2.73(\mathrm{P}=0.006)\end{array}$}} & $100.0 \%$ & $-0.53[-0.91,-0.15]$ & & & & \\
\hline & & & & & & & & & -2 & $\begin{array}{cc}-1 & 1 \\
\text { Favours [experimental] }\end{array}$ & $\begin{array}{c}1 \\
\text { Favours [control] }\end{array}$ & 2 \\
\hline
\end{tabular}


Table 3 Moderator analyses outcomes T1

\begin{tabular}{|c|c|c|c|c|c|c|c|}
\hline Variables & \# of studies & Pooled ES & L95 & U95 & $P$-value & $1^{2}$ & Meta-regression $p$-value \\
\hline Overall & 8 & -0.41 & -0.61 & -0.20 & $<0.001$ & $32 \%$ & \\
\hline \multicolumn{8}{|l|}{ Disease } \\
\hline Cancer & 1 & -0.45 & -1.05 & 0.15 & & & \\
\hline Other & 7 & -0.41 & -0.65 & -0.18 & 0.001 & $41 \%$ & \\
\hline Baseline depression level & & & & & & & 0.926 \\
\hline Mild to moderate & 5 & -0.42 & -0.72 & -0.11 & 0.007 & $44 \%$ & \\
\hline Moderately severe to severe & 3 & -0.43 & -0.75 & -0.11 & 0.009 & $26 \%$ & \\
\hline Level of guidance & & & & & & & 0.840 \\
\hline Guided & 5 & -0.37 & -0.62 & -0.13 & 0.002 & $26 \%$ & \\
\hline Self-directed & 3 & -0.49 & -0.96 & -0.02 & 0.042 & $56 \%$ & \\
\hline Mode of delivery & & & & & & & 0.840 \\
\hline Face to face & 5 & -0.37 & -0.62 & -0.13 & 0.002 & $26 \%$ & \\
\hline Not face to face & 3 & -0.49 & -0.96 & -0.02 & 0.042 & $56 \%$ & \\
\hline Provider & & & & & & & 0.840 \\
\hline Professional & 5 & -0.38 & -0.63 & -0.14 & 0.002 & $28 \%$ & \\
\hline Self-directed & 3 & -0.5 & -0.98 & -0.02 & 0.042 & $58 \%$ & \\
\hline \multicolumn{8}{|l|}{ Format } \\
\hline Individual & 6 & -0.33 & -0.55 & -0.11 & 0.004 & $25 \%$ & \\
\hline Group & 2 & -0.65 & -1.01 & -0.28 & 0.001 & $0 \%$ & \\
\hline Duration of Intervention & & & & & & & 1.000 \\
\hline$<300 \min$ & 4 & -0.47 & -0.85 & -0.09 & 0.016 & $58 \%$ & \\
\hline$\geq 300$ & 4 & -0.41 & -0.66 & -0.16 & 0.002 & $0 \%$ & \\
\hline \multicolumn{8}{|l|}{ Control Group } \\
\hline Active & 2 & -0.70 & -1.52 & 0.11 & 0.09 & $64 \%$ & \\
\hline Not active & 6 & -0.33 & -0.51 & -0.15 & $<0.001$ & $10 \%$ & \\
\hline \multicolumn{8}{|l|}{ Methodological Quality } \\
\hline Low & 1 & -0.49 & -1.03 & 0.04 & 0.072 & & \\
\hline Moderate & 7 & -0.41 & -0.64 & -0.17 & 0.001 & $40 \%$ & \\
\hline Length of Intervention & & & & & & & 0.858 \\
\hline$<3$ months & 5 & -0.43 & -0.70 & -0.17 & 0.001 & $15 \%$ & \\
\hline$\geq 3$ months & 3 & -0.41 & -0.81 & -0.02 & 0.042 & $60 \%$ & \\
\hline \multicolumn{8}{|c|}{ Depression Self-Management Skills } \\
\hline Decision-making & & & & & & & $0.016^{*}$ \\
\hline No & 3 & -0.75 & -1.08 & -0.42 & $<0.001$ & $0 \%$ & \\
\hline Yes & 5 & -0.23 & -0.41 & -0.05 & 0.011 & $0 \%$ & \\
\hline \multicolumn{8}{|l|}{ Problem-solving } \\
\hline No & 2 & -0.90 & -1.31 & -0.48 & $<0.001$ & $0 \%$ & \\
\hline Yes & 6 & -0.26 & -0.43 & -0.09 & 0.003 & $0 \%$ & \\
\hline \multicolumn{8}{|l|}{ Resource Utilization } \\
\hline No & 7 & -0.31 & -0.47 & -0.15 & $<0.001$ & $0 \%$ & \\
\hline Yes & 1 & -1.13 & -1.85 & -0.41 & 0.002 & & \\
\hline \multicolumn{8}{|l|}{ Partnerships with HCPs } \\
\hline No & 7 & -0.49 & -0.70 & -0.28 & $<0.001$ & $4 \%$ & \\
\hline Yes & 1 & -0.16 & -0.4 & 0.08 & 0.197 & & \\
\hline
\end{tabular}


Table 3 Moderator analyses outcomes T1 (Continued)

\begin{tabular}{|c|c|c|c|c|c|c|c|}
\hline Variables & $\#$ of studies & Pooled ES & L95 & U95 & $P$-value & $1^{2}$ & Meta-regression $p$-value \\
\hline Taking Action & & & & & & & $0.020^{*}$ \\
\hline No & 3 & -0.75 & -1.08 & -0.42 & $<0.001$ & $0 \%$ & \\
\hline Yes & 5 & -0.23 & -0.41 & -0.05 & 0.011 & $0 \%$ & \\
\hline Behavioural Activation & & & & & & & 1.000 \\
\hline No & 4 & -0.47 & -0.85 & -0.09 & 0.016 & $58 \%$ & \\
\hline Yes & 4 & -0.41 & -0.66 & -0.16 & 0.002 & $0 \%$ & \\
\hline Cognitive Restructuring & & & & & & & 0.297 \\
\hline No & 3 & -0.61 & -1.06 & -0.16 & 0.008 & $34 \%$ & \\
\hline Yes & 5 & -0.32 & -0.53 & -0.11 & 0.003 & $21 \%$ & \\
\hline Self-monitoring & & & & & & & 0.694 \\
\hline No & 5 & -0.45 & -0.71 & -0.19 & 0.001 & $12 \%$ & \\
\hline Yes & 3 & -0.38 & -0.78 & 0.02 & 0.065 & $57 \%$ & \\
\hline Health Habits & & & & & & & 0.283 \\
\hline No & 4 & -0.25 & -0.45 & -0.05 & 0.014 & $0 \%$ & \\
\hline Yes & 4 & -0.56 & -0.93 & -0.19 & 0.003 & $49 \%$ & \\
\hline \multicolumn{8}{|c|}{ Communicating about Depression } \\
\hline No & 7 & -0.34 & -0.53 & -0.14 & 0.001 & $17 \%$ & \\
\hline Yes & 1 & -0.78 & -1.29 & -0.27 & 0.003 & & \\
\hline Social Support & & & & & & & 0.279 \\
\hline No & 3 & -0.23 & -0.43 & -0.02 & 0.036 & $0 \%$ & \\
\hline Yes & 5 & -0.53 & -0.82 & -0.23 & $<0.001$ & $33 \%$ & \\
\hline Relaxation & & & & & & & 0.212 \\
\hline No & 3 & -0.21 & -0.42 & 0.00 & 0.053 & $0 \%$ & \\
\hline Yes & 5 & -0.53 & -0.82 & -0.25 & $<0.001$ & $32 \%$ & \\
\hline Self-tailoring & & & & & & & 0.747 \\
\hline No & 4 & -0.47 & -0.80 & -0.14 & 0.005 & $34 \%$ & \\
\hline Yes & 4 & -0.37 & -0.67 & -0.07 & 0.015 & $40 \%$ & \\
\hline Number of Skills & & & & & & & 0.311 \\
\hline $1-6$ & 4 & -0.56 & -0.88 & -0.24 & 0.001 & $6 \%$ & \\
\hline $7-13$ & 4 & -0.32 & -0.57 & -0.07 & 0.013 & $37 \%$ & \\
\hline
\end{tabular}

Random effect model was used to compute the pooled effect size.

${ }^{*} p<0.05$ indicating statistical significance

conversion [95\% CI $-0.82,-0.02$ ]. Removing the same three studies as identified for depression due to high pharmacological co-intervention $[78,93,94]$, the pooled effect size was significant, $-0.29[95 \%$ CI $-0.53,-0.06]$, with no heterogeneity, $\mathrm{I}^{2}=0 \%$. One study [95] was not entered into the meta-analysis and favoured the intervention.

For the T2 time period, 4 studies were included in the meta-analysis $[78,90,93,94]$. The pooled effect size was $-0.52[95 \%$ CI $-0.94,-0.10]$ with high heterogeneity, $\mathrm{I}^{2}=77 \%$. This was not significant after HK conversion. The one study [97] not entered into the meta-analysis reported a significant improvement in anxiety in the intervention group as compared to the control.

Health-related quality of life. Mental component score (MCS) of health-related quality of life. Five studies were included in the meta-analysis in the $\mathrm{T} 1$ period $[78,80,86,88,90]$. The pooled effect size was statistically significant with moderate heterogeneity, $0.43[0.09,0.76]$ with $\mathrm{I}^{2}=60 \%$. However, it was not significant after HK conversion. Removing the results reported by Barley et al., 2014 [78] did not improve heterogeneity. For T2, the 3 studies were entered in 
the meta-analysis and did not result in significant pooled effect sizes [84, 90, 91].

Physical component score. (PCS) of health-related quality of life Five studies were entered into the meta-analysis for the T1 period [78, 80, 84, 88, 90] and 3 studies for the T2 time period [78, 84, 90]. The pooled effect sizes were not significant at either time point.

Fatigue. For the T1 period, three studies were included in the meta-analysis $[80,83,94]$ and resulted in a significant pooled effect size of $-0.36[-0.67$, - 0.06] with moderate heterogeneity, $\mathrm{I}^{2}=50 \%$. The results were not significant if Sharpe, Walker [94] was removed from the analysis. For T2, only one study reported the needed data for meta-analysis [94] and the results were statistically significant with an effect size of $-0.60[-0.78,-0.41]$ in favour of the intervention. Of the three studies not included in the meta-analysis, two reported in favour of the intervention at the T1 and T2 time periods [95, 96], and the remaining study reported no significant effect on this outcome [97].

Glycemic control (HbA1c). Three studies were entered into the meta-analysis in the T1 period [87, 90, 91] and the results of the pooled effect size were not significant. At T2, 4 studies were included in the meta-analysis [87, 89-91] and the results were significant with an effect size of -0.35 [CI 95\% $-0.62,-0.07$ ] and no heterogeneity, $\mathrm{I}^{2}=0 \%$.

\section{Moderator analyses}

The results of the moderator analyses for the T1 time period are presented in Table 3. The three studies found to be outliers $[78,93,94]$ due to imbalanced pharmacological co-intervention were not included in these analyses. There was not enough data to perform meta-regression for the T2 period (4 studies total); however, 8 studies were included at T1. Meta-regressions were performed for the following 5 moderators, as there were 4 studies in each sub-group: duration of the intervention $(<300$ min or $\geq 300 \mathrm{~min}$ ), behavioural activation (yes/no), health habits (yes/no), self-tailoring (yes/no), and number of self-management skills included in the intervention [1-6 or 7-13]. None were found to be significant. Additional meta-regressions were run for the following 9 moderators including a minimum of 3 studies per sub-group: baseline depression level of the study sample (mild to moderate/moderately severe to severe), level of guidance (guided/self-directed), intervention provider (professional/selfdirected), length of the intervention ( $<3$ months $/ \geq$
3 months), decision-making (yes/no), taking action (yes/no), cognitive restructuring (yes/no), selfmonitoring (yes/no), and relaxation (yes/no). Of these, the results were significant only for the two self-management skills of decision-making $(p=$ $0.020)$ and taking action $(p=0.017)$.

\section{Discussion}

To our knowledge, this is the first systematic review to examine the effect of self-management interventions on reducing depressive symptoms among adults with chronic physical disease(s) and co-occurring depression. The results were drawn from the findings of 15 studies. Meta-analysis was conducted for two time periods for the primary outcome of depression as well as the secondary outcomes of anxiety, health-related quality of life (mental component and physical component), fatigue, and glycemic control. Analyses of potential moderators of intervention effect on the primary outcome were performed to identify active elements. Overall, the findings support: a) an effect of interventions on improving depression and anxiety as well as glycemic control at $\geq 6$-months post-baseline; b) intervention duration and intervention length were not found to impact effect; and c) some moderators merit further attention in future studies, including level of guidance and type of self-management skills included.

\section{Effect on participant outcomes}

The results of the review indicate a moderate effect of self-management interventions on depression and a small effect on anxiety. These results are consistent with the broader literature on self-management for individuals with depression or chronic physical diseases. A systematic review by Houle et al. (2013) found that self-management interventions reduced depressive symptomatology in the general adult population and improved functioning, self-efficacy, and self-management behaviours [65]. Findings related to relapse of depression were mixed. The results of the present review could not shed further light on this issue, as only three studies reported intervention and control group data at 12 or more months [78, 89, 93]. Another recent systematic review assessing the effect of face-to-face selfmanagement interventions for adults with a chronic diseases (not necessarily with co-morbid depression) found that efficacious interventions were more likely to include psychological coping or stress management strategies [27].

Results of the present review can also be compared to those of a review of psychotherapy for 
adults with depression (with or without chronic comorbid chronic conditions) that found the interventions to have a larger but still moderate effect size $(d=0.68)$ in improving depressive symptoms [100]. Reviews of the effect of psychotherapy on comorbid depression in adults with chronic physical diseases report between small and large effect sizes [101]. Due to the relatively small number of studies, strong comparisons or conclusions cannot be drawn; however, results suggest that depression self-management interventions for this population may have a similarly beneficial effect while generally being more cost-effective.

\section{Moderator analyses}

The analyses of moderators found no significant difference in intervention effect on depression based on intervention length or duration. These findings have important implications for the integration of such interventions into resource constrained clinical environments. Seeking evidence-based cost- and time-effective interventions is imperative for the sustainability of providing these in clinical practice [27]. As feasibility is a priority, further investigation of these intervention characteristics is warranted.

Self-directed interventions (no contact with an HCP or coach) did not have significantly lower effect sizes than guided ones. However, this must be interpreted with much caution as the sample size was very small. A number of reviews support the efficacy of minimally guided and self-directed interventions $[102-105,120]$. A review of self-directed psychological interventions found a small significant effect of interventions $(d=0.23$ at post-test, $d=0.28$ from 4 - to 12 months) on depression [121]. Only one trial to our knowledge has directly compared the effects of a guided (coached) and self-directed depression intervention for adults with chronic conditions [106]. This trial was excluded from our meta-analysis because of the active control group. The results indicated an overall significant benefit of coaching on depressive symptoms at 3 months; among those who were not receiving psychological treatment at study entry, the benefit was extended to 6 months. The increased effect is likely explained by the greater adherence to the self-care tools in the coached (guided) group [22, 103].

The results indicated that not all selfmanagement skills may be equally beneficial in improving depressive symptoms. Of the 13 selfmanagement skills examined, two of them, decision-making and taking action, were potentially significant moderators of the primary outcome of depression. Of the skills examined, six, drawn from the work of Lorig \& Holman (2003), are considered "core" self-management skills that are applicable across chronic diseases. The remaining seven skills were drawn from the literature specifically on the self-management of depression. The findings of this study parallel those of a previous review of nonpharmacological depression interventions for caregivers, which found that problem-solving, decisionmaking, and taking action were significant moderators of depression [70]. It is notable that neither review identified depression specific skills as significant moderators. Interestingly, a review of selfmanagement interventions in a different population, adults with low income or low health literacy, also found that problem-solving and taking action were more often included in efficacious interventions [69]. Due to limited data, it was not possible to examine problem-solving in this review. Together, the findings of these reviews suggest that developing core self-management skills to foster behaviour change might be more important than disease-specific self-management skills.

\section{Methodological quality}

The majority of studies were of moderate methodological quality, and none met all of the criteria. Due to insufficient sample size, it was not possible to examine the heterogeneity among studies of different methodological quality. Adherence rates were reported in nine of 15 studies, similar to a previous review of self-care interventions for anxiety or depression that found $55 \%$ of studies reported adherence measures [107]. A number of studies described the amount of time participants engaged in the intervention; however, no study indicated a minimal therapeutic dose or exposure to the intervention. More detailed standardized measures of adherence including activity or module completion, time spent, and active engagement have been proposed to address this issue [108]. The pre-established criteria, based on Cochrane Risk of Bias tool, were difficult to apply to self-directed interventions. For example, intervention fidelity becomes essentially synonymous with adherence in the case of self-directed interventions. In this case, blinding of participants to group allocation may be of greater importance as they are in essence the interventionists and frequently selfreport their own outcomes.

If attrition was $20 \%$ or less across the sample, the criterion was assessed as being met [71, 109]. However, in six of the 15 studies, attrition rates were notably higher in the intervention group as compared to the control [78, 84, 89-92] and no studies reported greater attrition in the control group. 
This raises concern regarding the potential impact of attritional bias on study outcomes [110]. Though four of these studies used intention-to-treat analyses, this may not entirely mitigate the impacts of this missing data [111]. Reporting the baseline characteristics of participants who were and were not included in analyses is recommended to help address this [111]. Further, previous work has addressed predictors of attrition of participants with depression from pharmacological trials, but this has not been thoroughly addressed in psychosocial trials $[112,113]$.

\section{Reported outcomes}

There was substantial variety in the outcomes reported across studies and measurement instruments used. Of the 38 outcomes measured across studies, only five were reported at least three times at one time point. Further, six instruments were used to measure the primary outcome of depression. These instruments were also used to establish the presence of at least mild symptoms of depression across the sample, a criterion for inclusion in this review. This is notable as a recent co-calibration study examining the variations in five commonly used depression self-report instruments found that the cut-off scores across scales were not equivalent [114]. The impact of this on the primary outcome could have resulted in an under- or over-estimation of intervention effect.

\section{Strengths and limitations}

The study methods were guided by the Cochrane Handbook and the PRISMA statement, and the protocol was registered with PROSPERO [38, 39]. The methods were outlined in detail and are reproducible. Given some terminological ambiguity in the literature regarding what constitutes a selfmanagement intervention, another strength of this review was the search terms applied were very inclusive. Interventions that were not self-described as self-management were included in the review based on the meeting the predetermined definition based on current self-management literature. This is in line with recommendations by Lorig and Holman (2003). However, due to the variations in definitions of self-management, it is possible that other teams would have identified different interventions for inclusion. Further, self-management interventions are recommended as part of a stepped care approach to depression management in which a sequence of treatments are provided based on an individual's response [115]. Lower intensity interventions, such as self-management, are initially delivered and treatment is 'stepped up' to higher intensity psychological interventions (e.g., pharmacotherapy, psychotherapy) for those who do not benefit from the initial treatment $[22,105,115$, 116]. Though four such interventions were screened at the full text stage, none were included as they did not meet the a priori inclusion criterion of providing non-therapeutically active control group data. Future research could evaluate the role of self-management within the structure of stepped care approach to intervention delivery.

The results should be interpreted with caution as the sample size was small with substantial heterogeneity, though this was found to be largely attributable to the confounding impact of pharmacotherapy. The limited number of studies prevented further examination of sources of heterogeneity and analyses of moderators was also conducted with a very small sample. There was only sufficient data to examine outcomes up to 6 months; longer-term outcome data is needed. Further, most of the included studies were focused on those with cancer or diabetes. Though the findings offer potential future avenues for exploration, further evidence is required to investigate longerterm outcomes, sources of heterogeneity, and possible differences in chronic physical disease populations.

\section{Conclusion}

This is the first systematic review to examine the effect of self-management interventions on depression in adults with co-occurring chronic physical diseases. The findings indicate the interventions reduced depression with a moderate effect size and anxiety with a small effect size. Impact of the interventions on other psychosocial and physical health outcomes was mixed. Recommendations include further evaluation of the impact on the amount of guidance, length, and duration of interventions, as selfdirected, shorter and thereby less resource intensive interventions may be effective. Including self-management skills of decision-making and taking action in future interventions is also recommended.

\section{Abbreviations}

BDI-II: Beck depression inventory-II; BDI: Beck depression inventory; C: Control condition; CBT: Cognitive behavioural therapy; CES-D: Centre for epidemiological studies-depression; CHD: Coronary heart disease; Cl: Confidence interval; CNS: Central nervous system; COPD: Chronic obstructive pulmonary disease; DSM: Diagnostic and statistical manual of 


\section{Appendix 1}

Table 4 Depression self-management skills included in the interventions

\begin{tabular}{|c|c|c|c|c|c|c|c|c|c|c|c|c|}
\hline & $\begin{array}{l}\text { Barley } \\
\text { et al. } \\
\text { (2014) } \\
{[78]}\end{array}$ & $\begin{array}{l}\text { Boele } \\
\text { et al. } \\
\text { (2018) } \\
{[80]}\end{array}$ & $\begin{array}{l}\text { Espahbodi } \\
\text { et al. } \\
\text { (2015) [82] }\end{array}$ & $\begin{array}{l}\text { Fischer } \\
\text { et al. } \\
\text { (2015) } \\
\text { [83] \& } \\
\text { Schroder } \\
\text { et al. } \\
(2014)^{*} \\
\text { [92] }\end{array}$ & $\begin{array}{l}\text { Lamers } \\
\text { et al. } \\
(2010) \\
{[86]}\end{array}$ & $\begin{array}{l}\text { Lee } \\
\text { et al. } \\
\text { (2014) } \\
{[88]}\end{array}$ & $\begin{array}{l}\text { Moncrief } \\
\text { et al. } \\
(2016) \\
{[89]}\end{array}$ & $\begin{array}{l}\text { Penckofer } \\
\text { et al. } \\
(2012) \\
{[90]}\end{array}$ & $\begin{array}{l}\text { Rees } \\
\text { et al. } \\
\text { (2016) }\end{array}$ & $\begin{array}{l}\text { Sharpe } \\
\text { et al. (2004) } \\
\text { [93], [93] } \\
\text { Sharpe } \\
\text { et al. (2014) } \\
\text { [94], Strong } \\
\text { et al. (2008) } \\
\text { [95], \& } \\
\text { Walker } \\
\text { et al. } \\
\text { (2014)† [97] }\end{array}$ & $\begin{array}{l}\text { Thorton } \\
\text { et al. } \\
(2009) \\
{[96]}\end{array}$ & Total \\
\hline Decision- & 1 & 1 & 0 & 1 & 1 & 0 & 1 & 0 & 1 & 1 & 1 & 8 \\
\hline
\end{tabular}

\section{Making}

Often occurs in

the context of

problem-solving

and is based on

having enough

and appropriate

information to

meet common

changes associ-

ated with chronic

illness [25].

\section{Problem-solving 1}

Using a

structured

approach and

learning skills

such as problem

definition,

generating

solutions,

implementation,

and evaluation of

results to move

towards a

solution $[25,29]$.

\section{Resource}

Utilization

Learning how to

seek out many

resources (using

different sources)

[25].

\section{Forming}

Partnerships

with HCPs

Learning how to

provide disease-

related feedback

to HCPs and

make informed

treatment deci-

sions and discuss

with HCPs [25].

Taking Action

Making a plan

and carrying it

out, learning skills

involved in

behaviour

change [25].

0

0

Activation 
Table 4 Depression self-management skills included in the interventions (Continued)

\begin{tabular}{|c|c|c|c|c|c|c|c|c|c|c|c|c|}
\hline & $\begin{array}{l}\text { Barley } \\
\text { et al. } \\
(2014) \\
{[78]}\end{array}$ & $\begin{array}{l}\text { Boele } \\
\text { et al. } \\
(2018) \\
{[80]}\end{array}$ & $\begin{array}{l}\text { Espahbodi } \\
\text { et al. } \\
\text { (2015) [82] }\end{array}$ & $\begin{array}{l}\text { Fischer } \\
\text { et al. } \\
\text { (2015) } \\
\text { [83] \& } \\
\text { Schroder } \\
\text { et al. } \\
(2014)^{*} \\
\text { [92] }\end{array}$ & $\begin{array}{l}\text { Lamers } \\
\text { et al. } \\
(2010) \\
{[86]}\end{array}$ & $\begin{array}{l}\text { Lee } \\
\text { et al. } \\
\text { (2014) } \\
{[88]}\end{array}$ & $\begin{array}{l}\text { Moncrief } \\
\text { et al. } \\
\text { (2016) } \\
{[89]}\end{array}$ & $\begin{array}{l}\text { Penckofer } \\
\text { et al. } \\
(2012) \\
{[90]}\end{array}$ & $\begin{array}{l}\text { Rees } \\
\text { et al. } \\
(2016)\end{array}$ & $\begin{array}{l}\text { Sharpe } \\
\text { et al. (2004) } \\
\text { [93], [93] } \\
\text { Sharpe } \\
\text { et al. (2014) } \\
\text { [94], Strong } \\
\text { et al. (2008) } \\
\text { [95], \& } \\
\text { Walker } \\
\text { et al. } \\
\text { (2014)† [97] }\end{array}$ & $\begin{array}{l}\text { Thorton } \\
\text { et al. } \\
\text { (2009) } \\
{[96]}\end{array}$ & Total \\
\hline \multicolumn{13}{|l|}{$\begin{array}{l}\text { Learning to } \\
\text { gradually increase } \\
\text { positive activities } \\
\text { through effective } \\
\text { goal setting [29] }\end{array}$} \\
\hline $\begin{array}{l}\text { Cognitive } \\
\text { Restructuring } \\
\text { Learning to } \\
\text { identify } \\
\text { depressive self- } \\
\text { talk, challenge it, } \\
\text { and come up } \\
\text { with fair-realistic } \\
\text { ways of evaluat- } \\
\text { ing situations } \\
\text { [29]. }\end{array}$ & 0 & 1 & 0 & 1 & 1 & 0 & 1 & 1 & 0 & 0 & 0 & 5 \\
\hline $\begin{array}{l}\text { Self-Monitoring } \\
\text { Monitoring } \\
\text { depression } \\
\text { symptoms and } \\
\text { evaluating } \\
\text { whether current } \\
\text { strategies are } \\
\text { working } \\
\text { effectively and, } \\
\text { when necessary, } \\
\text { reassessing } \\
\text { treatment plans } \\
\text { [63]. }\end{array}$ & 1 & 0 & 0 & 0 & 1 & 0 & 1 & 1 & 1 & 0 & 0 & 5 \\
\hline $\begin{array}{l}\text { Health Habits } \\
\text { Learning about } \\
\text { the links between } \\
\text { health habits } \\
\text { (e.g., sleep, diet) } \\
\text { and mental } \\
\text { health. Learning } \\
\text { how to enact } \\
\text { helpful health } \\
\text { related habits [64, } \\
65 \text { ]. }\end{array}$ & 0 & 0 & 0 & 1 & 0 & 1 & 1 & 1 & 0 & 0 & 1 & 5 \\
\hline $\begin{array}{l}\text { Communicating } \\
\text { about } \\
\text { Depression } \\
\text { Learning to } \\
\text { explain what it } \\
\text { means to } \\
\text { experience } \\
\text { depression to } \\
\text { family members, } \\
\text { friends, and } \\
\text { colleagues [117]. }\end{array}$ & 0 & 0 & 0 & 0 & 0 & 0 & 0 & 1 & 0 & 0 & 0 & 1 \\
\hline $\begin{array}{l}\text { Social Support } \\
\text { Arranging } \\
\text { instrumental and } \\
\text { emotional }\end{array}$ & 1 & 1 & 0 & 1 & 0 & 1 & 1 & 1 & 0 & 0 & 1 & 7 \\
\hline
\end{tabular}


Table 4 Depression self-management skills included in the interventions (Continued)

\begin{tabular}{|c|c|c|c|c|c|c|c|c|c|c|c|c|}
\hline & $\begin{array}{l}\text { Barley } \\
\text { et al. } \\
(2014) \\
{[78]}\end{array}$ & $\begin{array}{l}\text { Boele } \\
\text { et al. } \\
(2018) \\
{[80]}\end{array}$ & $\begin{array}{l}\text { Espahbodi } \\
\text { et al. } \\
\text { (2015) [82] }\end{array}$ & $\begin{array}{l}\text { Fischer } \\
\text { et al. } \\
\text { (2015) } \\
\text { [83] \& } \\
\text { Schroder } \\
\text { et al. } \\
(2014)^{*} \\
{[92]}\end{array}$ & $\begin{array}{l}\text { Lamers } \\
\text { et al. } \\
(2010) \\
{[86]}\end{array}$ & $\begin{array}{l}\text { Lee } \\
\text { et al. } \\
(2014) \\
{[88]}\end{array}$ & $\begin{array}{l}\text { Moncrief } \\
\text { et al. } \\
(2016) \\
{[89]}\end{array}$ & $\begin{array}{l}\text { Penckofer } \\
\text { et al. } \\
\text { (2012) } \\
{[90]}\end{array}$ & $\begin{array}{l}\text { Rees } \\
\text { et al. } \\
(2016)\end{array}$ & $\begin{array}{l}\text { Sharpe } \\
\text { et al. (2004) } \\
\text { [93], [93] } \\
\text { Sharpe } \\
\text { et al. (2014) } \\
\text { [94], Strong } \\
\text { et al. (2008) } \\
\text { [95], \& } \\
\text { Walker } \\
\text { et al. } \\
\text { (2014)† [97] }\end{array}$ & $\begin{array}{l}\text { Thorton } \\
\text { et al. } \\
\text { (2009) } \\
{[96]}\end{array}$ & Total \\
\hline \multicolumn{13}{|l|}{$\begin{array}{l}\text { support [117- } \\
119] \text {. Involving } \\
\text { close friends/ } \\
\text { family in } \\
\text { treatment and } \\
\text { support [117, } \\
118] \text {. }\end{array}$} \\
\hline $\begin{array}{l}\text { Relaxation } \\
\text { Maintaining or } \\
\text { developing } \\
\text { activities related } \\
\text { to relaxation (e.g., } \\
\text { meditation, } \\
\text { breathing } \\
\text { exercises). }\end{array}$ & 0 & 0 & 1 & 1 & 0 & 1 & 1 & 1 & 0 & 0 & 1 & 6 \\
\hline $\begin{array}{l}\text { Self-tailoring } \\
\text { Learning to use } \\
\text { other self- } \\
\text { management } \\
\text { skills based on a } \\
\text { personal evalu- } \\
\text { ation of your } \\
\text { own needs. }\end{array}$ & 1 & 1 & 0 & 0 & 1 & 0 & 1 & 1 & 1 & 1 & 0 & 7 \\
\hline Total & 7 & 6 & 2 & 8 & 7 & 4 & 11 & 8 & 6 & 4 & 5 & \\
\hline
\end{tabular}




\section{Appendix 2}

Ovid MEDLINE(R) In-Process \& Other Non-Indexed Citations and Ovid MEDLINE(R) $<1996$ to June 25, 2018>

\begin{tabular}{|c|c|c|c|}
\hline \# & Search Statement & Results & Annotation \\
\hline 1 & Depression/ & 77227 & \\
\hline 2 & $\begin{array}{l}\text { depressive disorder/ or depressive disorder, major/ or depressive disorder, } \\
\text { treatment-resistant/ or dysthymic disorder/ }\end{array}$ & 67536 & \\
\hline 3 & (depress* or low mood or dysthymia*).kf,tw. & 297911 & \\
\hline 4 & 1 or 2 or 3 & 318989 & \\
\hline 5 & clinical trial/ or exp controlled clinical trial/ & 590743 & \\
\hline 6 & $\begin{array}{l}\text { controlled clinical trials as topic/ or non-randomized controlled trials as topic/ or } \\
\text { randomized controlled trials as topic/ or equivalence trials as topic/ or } \\
\text { pragmatic clinical trials as topic/ }\end{array}$ & 113995 & \\
\hline 7 & $\begin{array}{l}\text { control groups/ or cross-over studies/ or double-blind method/ or random } \\
\text { allocation/ or single-blind method/ }\end{array}$ & 212242 & \\
\hline 8 & Therapies, Investigational/ & 1260 & \\
\hline 9 & $\begin{array}{l}\text { (random }{ }^{*} \text { or mask }{ }^{*} \text { or rct or rcts or blind }{ }^{*} \text { or assign }{ }^{*} \text { or cross over or crossover } \\
\text { or pragmatic or quasi experiment* or wait list or waitlist or delayed treatment } \\
\text { group or control* } \text { trial }^{*} \text { or control }{ }^{*} \text { group }{ }^{*} \text { or clinical trial }{ }^{*} \text { or non-inferior } \text { or }^{*} \\
\text { noninferior*).kf,tw. }\end{array}$ & 1545388 & \\
\hline 10 & 5 or 6 or 7 or 8 or 9 & 1857311 & \\
\hline 11 & self care/ or self-management/ & 25390 & \\
\hline 12 & Self-Help Groups/ & 5612 & \\
\hline 13 & behavior therapy/ & 13901 & \\
\hline 14 & health education/ or patient education as topic/ & 89427 & \\
\hline 15 & Decision Making/ & 65100 & \\
\hline 16 & Problem Solving/ & 14796 & \\
\hline 17 & 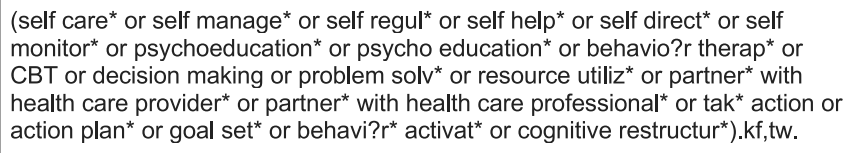 & 182862 & \\
\hline 18 & 11 or 12 or 13 or 14 or 15 or 16 or 17 & 331345 & \\
\hline 19 & 4 and 10 and 18 & 7279 & \\
\hline
\end{tabular}

Fig. 4 Sample Search Strategy from Ovid Medline conducted June 25th, 2018 


\section{Appendix 3}

Funnel Plots for Depression (primary outcome)

Funnel plot of intervention effect estimates for individual studies for depression at T1 - Baseline to $<6$ months postbaseline

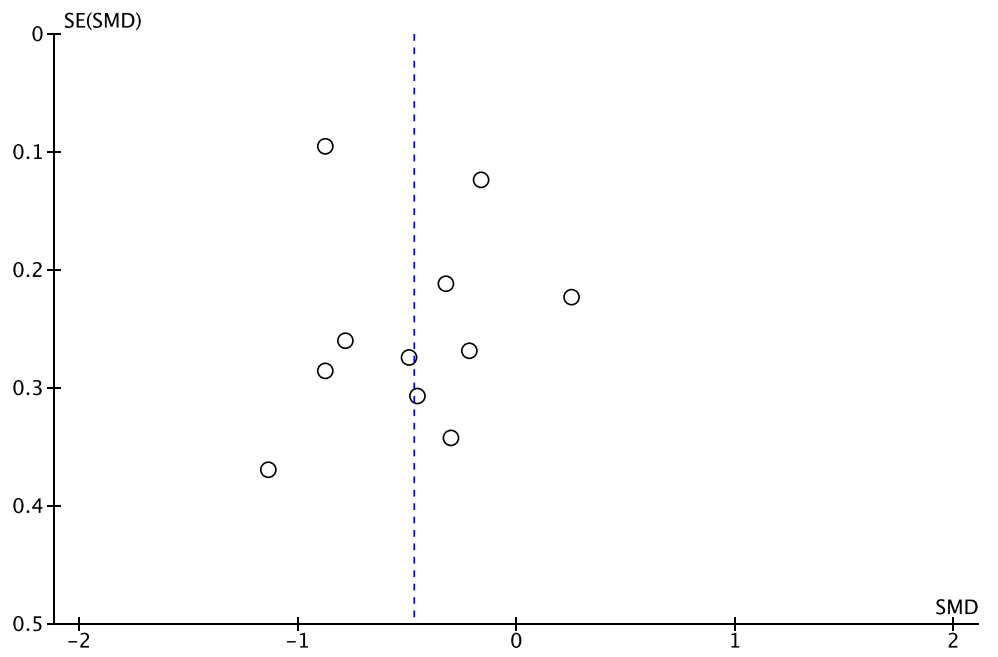

Fig. 5 Funnel plot of intervention effect estimates for individual studies for depression at T1 - Baseline to $<6$ months

Funnel plot of intervention effect estimates for individual studies for depression at T2 - $\geq 6$ months post-baseline

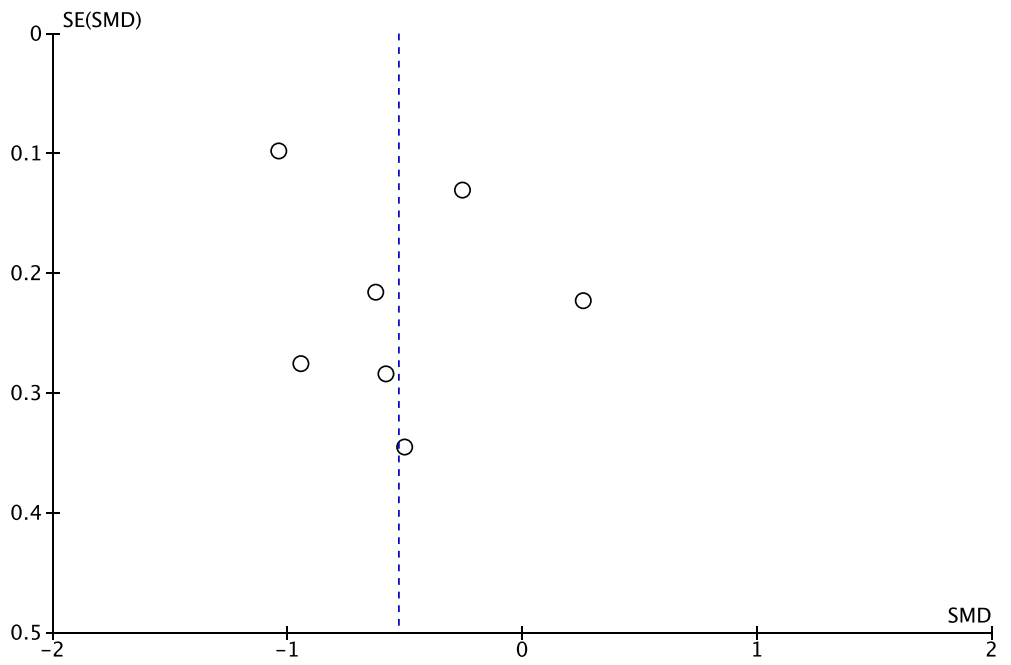

Fig. 6 Funnel plot of intervention effect estimates for individual studies for depression at T2 - $\geq 6$ months post-baseline 


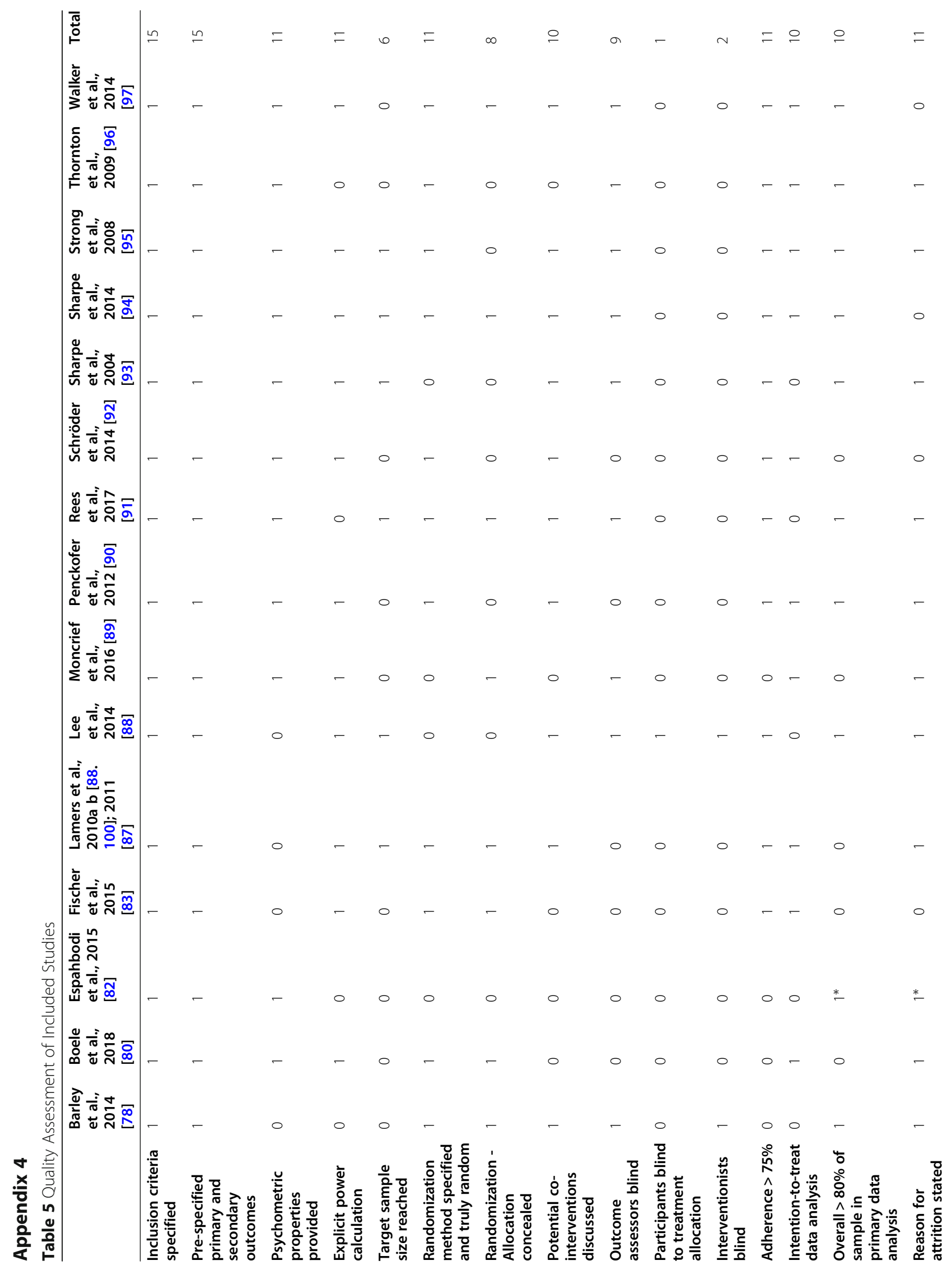




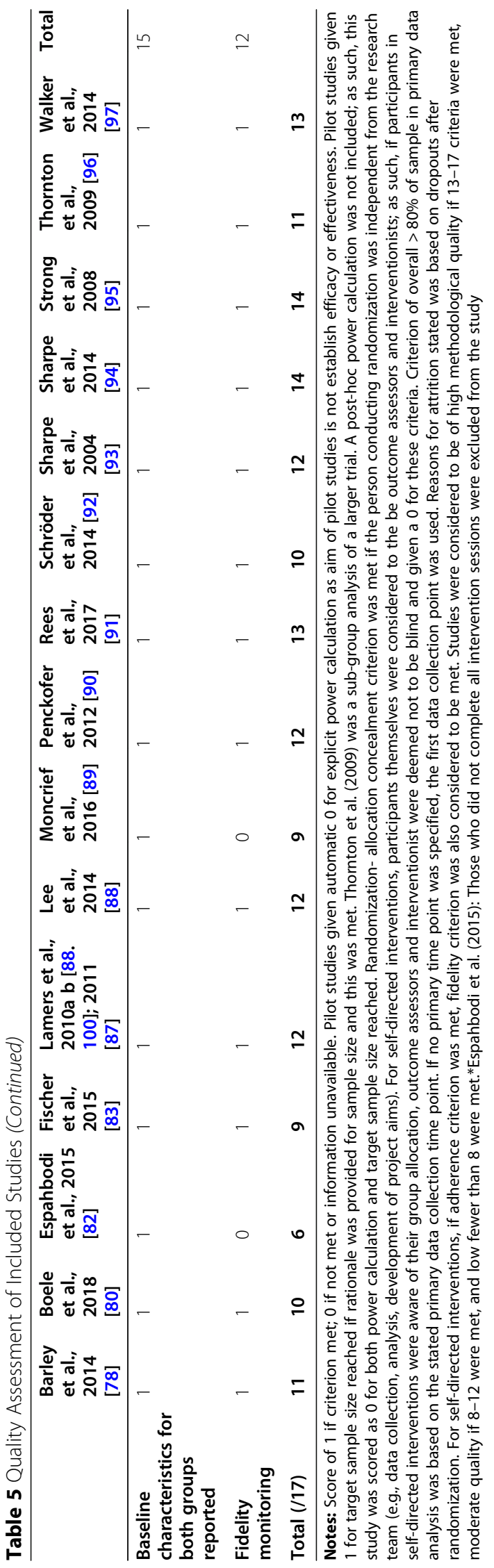




\section{Appendix 5}

\section{Forest plots of secondary outcomes}

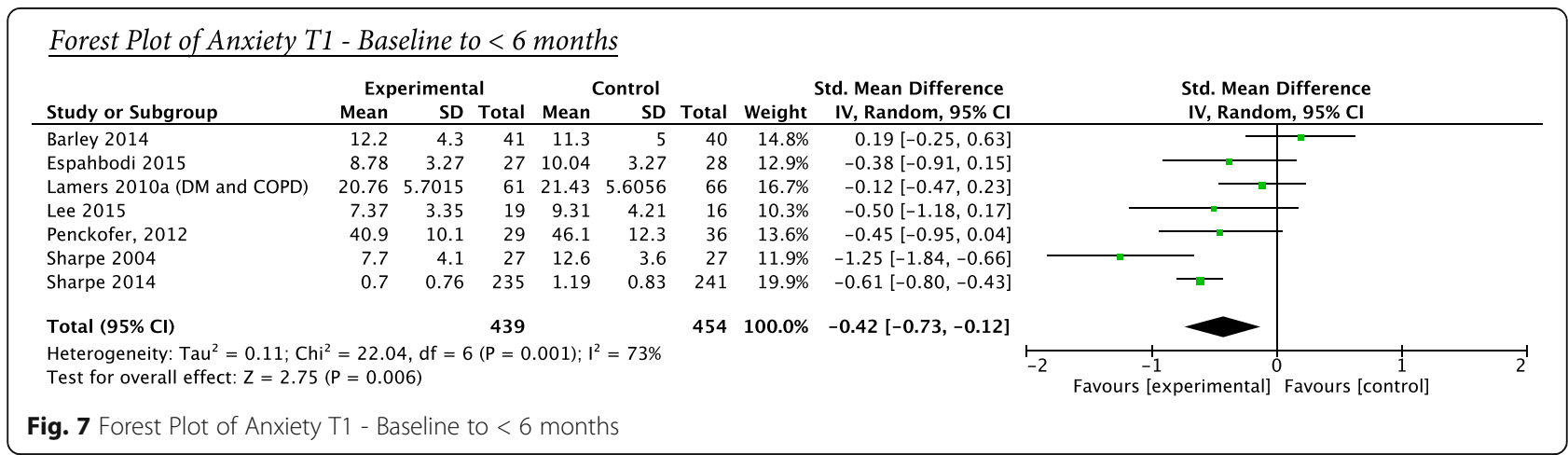

\section{Forest Plot of Anxiety T2 - $\geq 6$ months}

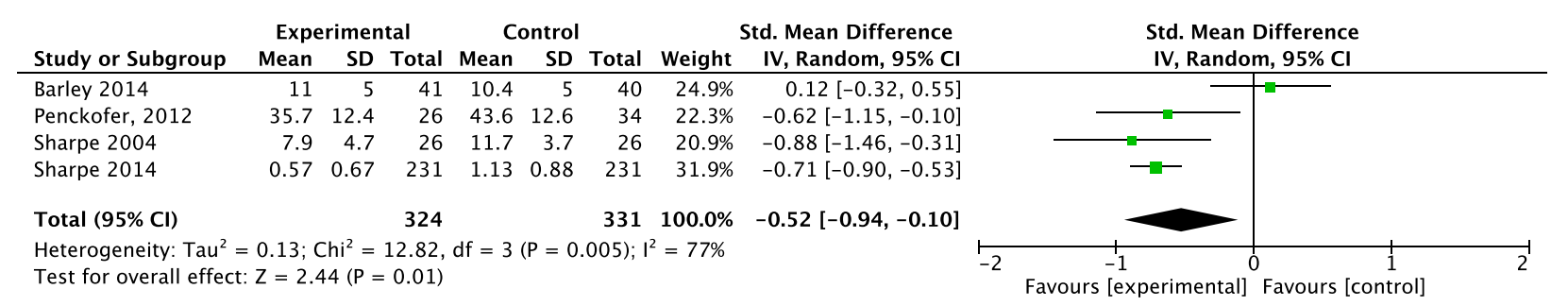

Fig. 8 Forest Plot of Anxiety T2 $\geq 6$ months post-baseline 


\begin{tabular}{|c|c|c|c|c|c|c|c|c|c|c|c|}
\hline \multicolumn{12}{|c|}{ Forest Plot of MCS T1 - Baseline to $<6$ months } \\
\hline \multirow[b]{2}{*}{ Study or Subgroup } & \multicolumn{3}{|c|}{ Experimental } & \multicolumn{3}{|c|}{ Control } & \multicolumn{3}{|c|}{ Std. Mean Difference } & & \\
\hline & Mean & SD & Total & Mean & SD & Total & Weight & IV, Random, $95 \% \mathrm{CI}$ & & & \\
\hline Barley 2014 & 31.4 & 10.8 & 41 & 30.8 & 11 & 40 & $22.0 \%$ & $0.05[-0.38,0.49]$ & & & \\
\hline Boele et al., 2018 & 40.56 & 9.8 & 18 & 32.4 & 8.9 & 28 & $15.9 \%$ & $0.87[0.25,1.49]$ & & & \\
\hline Lamers 2010a (DM and COPD) & 39.84 & 9.0198 & 110 & 38.3 & 8.9787 & 109 & $28.7 \%$ & $0.17[-0.09,0.44]$ & & - & \\
\hline Lee 2015 & 45.56 & 5.36 & 19 & 37.09 & 9.76 & 16 & $13.5 \%$ & $1.08[0.36,1.79]$ & & & \\
\hline Penckofer, 2012 & 47.4 & 10.8 & 29 & 43 & 9.8 & 36 & $19.9 \%$ & $0.42[-0.07,0.92]$ & & & \\
\hline Total $(95 \% \mathrm{Cl})$ & & & 217 & & & 229 & $100.0 \%$ & $0.43[0.09,0.76]$ & & & \\
\hline \multicolumn{6}{|c|}{$\begin{array}{l}\text { Heterogeneity: } \mathrm{Tau}^{2}=0.08 ; \mathrm{Chi}^{2}=10.08, \mathrm{df}=4(\mathrm{P}=0.04) ; \mathrm{I}^{2}=60 \% \\
\text { Test for overall effect: } Z=2.50(P=0.01)\end{array}$} & & & & -2 & 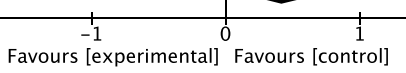 & 2 \\
\hline . 9 Forest Plot of MCS 7 & Basel & line to & $5 \mathrm{mc}$ & onth & & & & & & & \\
\hline
\end{tabular}

Forest Plot of MCS T2 - > 6 months post-baseline

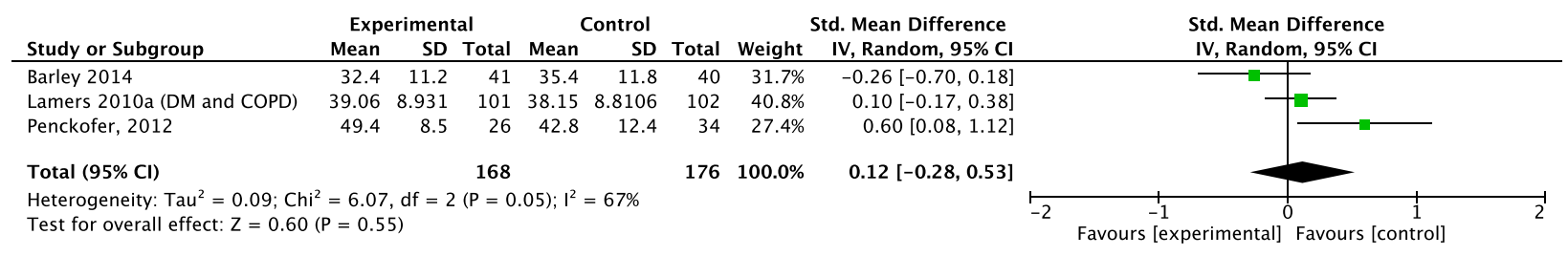

Fig. 10 Forest Plot of MCS T2 $\geq 6$ months post-baseline 


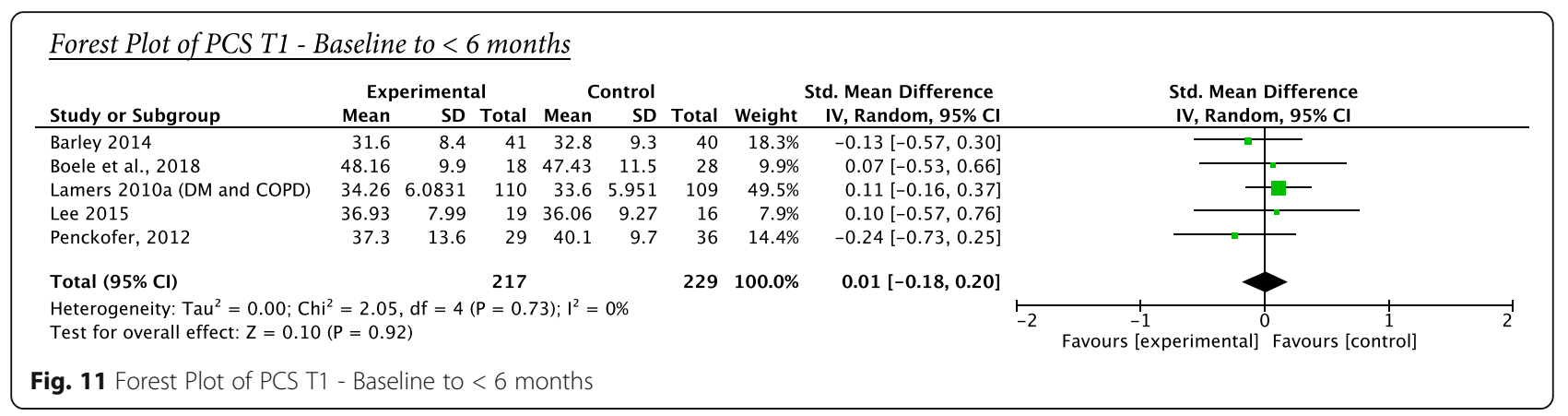

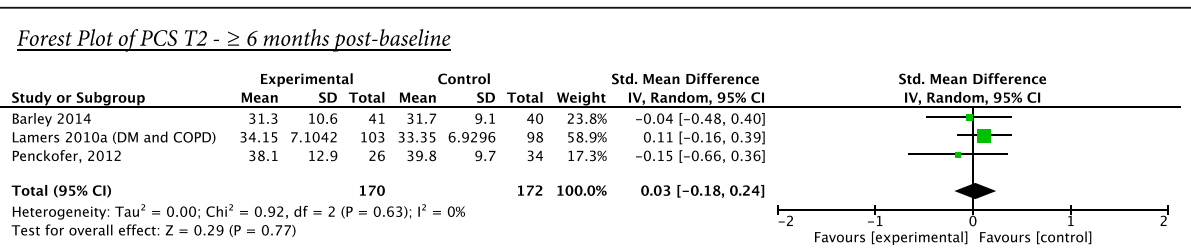

Fig. 12 Forest Plot of PCS T2 $\geq 6$ months post-baseline 


\begin{tabular}{|c|c|c|c|c|c|c|c|c|c|c|c|c|}
\hline \multicolumn{13}{|c|}{ Forest Plot of Fatigue T1 $-<6$ months } \\
\hline \multirow[b]{2}{*}{ Study or Subgroup } & \multicolumn{3}{|c|}{ Experimental } & \multicolumn{3}{|c|}{ Control } & \multicolumn{2}{|r|}{ Std. Mean Difference } & \multirow{2}{*}{\multicolumn{4}{|c|}{$\begin{array}{l}\text { Std. Mean Difference } \\
\text { IV, Random, } 95 \% \mathrm{CI}\end{array}$}} \\
\hline & Mean & SD & Total & Mean & SD & Total & Weight & IV, Random, $95 \% \mathrm{Cl}$ & & & & \\
\hline Boele et al., 2018 & 79.94 & 27.8 & 18 & 96.5 & 16.5 & 28 & $17.9 \%$ & $-0.75[-1.37,-0.14]$ & & - & & \\
\hline Fischer 2015 & 70.15 & 16.06 & 45 & 70.87 & 15.22 & 45 & $29.5 \%$ & $-0.05[-0.46,0.37]$ & & & - & \\
\hline Sharpe 2014 & 46.6 & 25.3 & 235 & 56.7 & 24.3 & 241 & $52.6 \%$ & $-0.41[-0.59,-0.23]$ & & & & \\
\hline Total $(95 \% \mathrm{Cl})$ & & & 298 & & & 314 & $100.0 \%$ & $-0.36[-0.67,-0.06]$ & & & & \\
\hline \multicolumn{9}{|c|}{$\begin{array}{l}\text { Heterogeneity: } \mathrm{Tau}^{2}=0.04 ; \mathrm{Chi}^{2}=4.02, \mathrm{df} \\
\text { Test for overall effect: } \mathrm{Z}=2.33(\mathrm{P}=0.02)\end{array}$} & -2 & $\begin{array}{c}-1 \\
-1 \\
\text { Favours [experimental] }\end{array}$ & $\begin{array}{lc}0 & 1 \\
\text { Favours [control] }\end{array}$ & 2 \\
\hline \multicolumn{13}{|c|}{ Fig. 13 Forest Plot of Fatigue $\mathrm{T} 1$ - Baseline to $<6$ months } \\
\hline
\end{tabular}

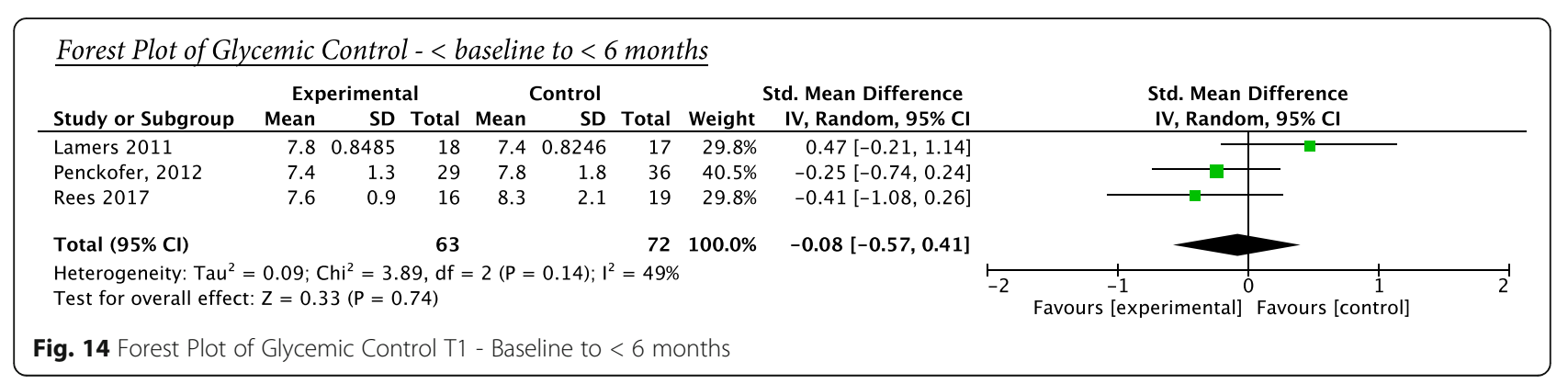




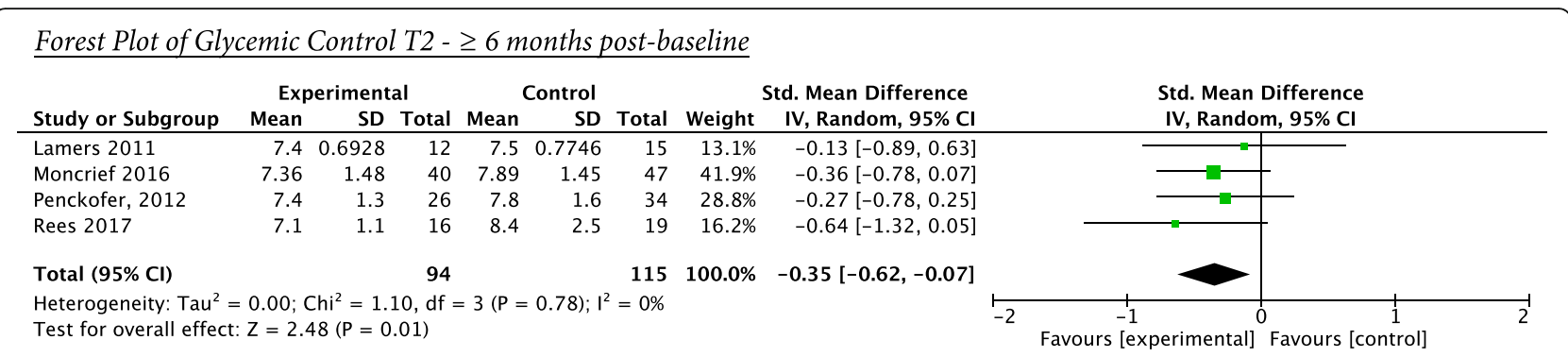

Fig. 15 Forest Plot of Glycemic Control T2 $\geq 6$ months post-baseline

mental disorders; ER: Emergency room; ES: Effect size (hedge's g calculated at $95 \%$ confidence level); HADS-D: Hospital anxiety and depression scaledepression; HbA1c: Hemoglobin A1c test for glycemic control; HCP: Healthcare professional; HRQoL: Health related quality of life and includes; PCS: Physical health composite scale; MCS: Mental health composite scale; ICD: International classification of diseases; IQR: Interquartile range; KH: Knapp-Hartung; MS: Multiple sclerosis; PHQ-9: Patient health questionnaire; PRESS: Peer Review for electronic search strategies; PRISMA: Preferred reporting items for systematic reviews and meta-analyses; PST: Problem-solving therapy; QoL: Quality of life; RCT: Randomized controlled trial; SD: Standard deviation; T < C: control superior to treatment; $\mathrm{T}=\mathrm{C}$ : no significant differences between treatment and control conditions; $T>C$ : treatment significantly superior to control; $\mathrm{T}$ : Treatment condition; WLC: Waitlist control group

\section{Acknowledgements}

Not applicable.

\section{Authors' contributions}

LOB: Conceptualized and designed the work, collected, analyzed, and interpreted data, and drafted the manuscript. SL: Conceptualized and designed the work, contributed to data collection, and assisted with interpreting data, and substantially revised the manuscript. NF: Assisted in designing the work, interpreting the data, and substantially revised the manuscript. CC: Conducted data collection and substantially revised the manuscript. JS: Conducted data collection and substantially revised the manuscript. JC: Contributed to conceptualizing and designing the work and substantially revised the manuscript. EEMM: Contributed to data analysis and interpretation and substantially revised the manuscript. JK: Contributed to data collection and substantially revised the manuscript. KK: Contributed to data collection. EB: Conducted some data analysis, assisted with data interpretation, and substantially revised manuscript. CG: Contributed to data interpretation and substantially revised manuscript. All authors read and approved the final manuscript.

\section{Funding}

This work was supported by the Fonds de recherche santé Québec (FRQS), the Réseau de recherche en interventions en sciences infirmières (RRISIQ), Dr. Lambert's Tier 2 Canada Research Chair and the McGill Nursing Collaborative for Education and Innovation in Patient and Family Centered Care. All bodies listed provided general funding to the named author to support their research; however, these bodies had no role or influence in the design of the study or collection, analysis, or interpretation of the data or writing the manuscript.

\section{Availability of data and materials}

The datasets used and/or analysed during the current study are available from the corresponding author on reasonable request.

\section{Declarations}

Ethics approval and consent to participate Not applicable.

\section{Consent for publication}

Not applicable.

\section{Competing interests}

The authors declare that they have no competing interests.

\section{Author details}

${ }^{1}$ Ingram School of Nursing, McGill University, Montreal, Canada. ${ }^{2}$ St. Mary's Research Centre, Montreal, Canada. ${ }^{3}$ Centre for Nursing Research, Montreal, Canada. ${ }^{4}$ Healthcare Sciences and e-Health, Department of Women's and Children's Health, Uppsala University, Uppsala, Sweden. ${ }^{5}$ Epidemiology, Biostatistics and Occupational Health, McGill University, Montreal, Canada. ${ }^{6}$ Department of Epidemiology, Biostatistics, and Occupational Health, McGill University Montreal, Montreal, Canada. ${ }^{7}$ CIUSSS du

Centre-Sud-de-l'̂le-de-Montréa, Montreal, Canada. ${ }^{8}$ Trillium Lakelands District School Board, Lindsay, Canada. ${ }^{9}$ Faculty of Nursing Sciences, Université de Montreal, Montreal, Quebec, Canada.

Received: 19 January 2021 Accepted: 28 September 2021

Published online: 20 November 2021

\section{References}

1. World Health Organization. Depression Fact Sheet: World Health Organization; 2018 [Available from: http://www.who.int/mediacentre/fa ctsheets/fs369/en/.

2. Kessler RC, Bromet EJ. The epidemiology of depression across cultures. Annu Rev Public Health. 2013;34(1):119-38. https://doi.org/10.1146/annurevpublhealth-031912-114409.

3. Lim GY, Tam WW, Lu Y, Ho CS, Zhang MW, Ho RC. Prevalence of depression in the community from 30 countries between 1994 and 2014. Sci Rep. 2018, 8(1):2861. https://doi.org/10.1038/s41598-018-21243-x.

4. World Health Organization. Global Health estimates 2016: deaths by cause, age, sex, by country and by region, 2000-2016. Geneva: World Health Organization; 2018.

5. Moussavi S, Chatterji S, Verdes E, Tandon A, Patel V, Ustun B. Depression, chronic diseases, and decrements in health: results from the World Health Surveys. Lancet (London, England). 2007;370(9590):851-8.

6. Katon WJ. Epidemiology and treatment of depression in patients with chronic medical illness. Dialogues Clin Neurosci. 2011;13(1):7-23. https://doi. org/10.31887/DCNS.2011.13.1/wkaton.

7. Li H, Ge S, Greene B, Dunbar-Jacob J. Depression in the context of chronic diseases in the United States and China. Int J Nurs Sci. 2018;6(1):117-22. https://doi.org/10.1016/j.jinss.2018.11.007.

8. World Health Organization \& Public Health Agency of Canada. Preventing chronic diseases: a vital investment. Geneva: World Health Organization; 2005. https://apps.who.int/iris/handle/10665/43314.

9. World Health Organization. Noncommunicable diseases 2018 [Available from: https://www.who.int/news-room/fact-sheets/detail/noncommunica ble-diseases. Accessed Dec 2021.

10. Gonzalez JS, Peyrot M, McCarl LA, Collins EM, Serpa L, Mimiaga MJ, et al. Depression and diabetes treatment nonadherence: a meta-analysis. Diabetes Care. 2008;31(12):2398-403. https://doi.org/10.2337/dc08-1341.

11. Kravitz RL, Ford DE. Introduction: chronic medical conditions and depression--the view from primary care. Am J Med. 2008;121(11 Suppl 2): S1-7. https://doi.org/10.1016/j.amjmed.2008.09.007. 
12. National Institute for Health and Clinical Excellence. Depression: the treatment and Management of Depression in adults (updated edition) Leicester (UK): British Psychological Society; 2010.

13. Cuijpers P, Smit F. Subclinical depression: a clinically relevant condition? Tijdschr Psychiatr. 2008;50(8):519-28.

14. Tuithof M, Ten Have M, van Dorsselaer S, Kleinjan M, Beekman A, de Graaf R. Course of subthreshold depression into a depressive disorder and its risk factors. J Affect Disord. 2018;241:206-15. https://doi.org/10.1016/j.jad.2018. 08.010.

15. Clarke DM, Currie KC. Depression, anxiety and their relationship with chronic diseases: a review of the epidemiology, risk and treatment evidence. Med J Aust. 2009;190(S7):S54-60. https://doi.org/10.5694/j.132 6-5377.2009.tb02471.x.

16. Craven MA, Bland R. Depression in primary care: current and future challenges. Can J Psychiatry. 2013;58(8):442-8. https://doi.org/10.1177/ 070674371305800802.

17. Mojtabai R, Olfson M, Sampson NA, Jin R, Druss B, Wang PS, et al. Barriers to mental health treatment: results from the National Comorbidity Survey Replication. Psychol Med. 2011:41(8):1751-61. https://doi.org/10.1017/ S0033291710002291.

18. Renn BN, Hoeft TJ, Lee HS, Bauer AM, Areán PA. Preference for in-person psychotherapy versus digital psychotherapy options for depression: survey of adults in the U.S. NPJ Digital Med. 2019;2(1):6.

19. Fournier $L$, Roberge $P$, Brouillet $H$. Faire face à la dépression au Québec. Montréal: Protocole de soins à l'intention des intervenants de première ligne Centre de recherche du CHUM; 2012.

20. Patten SB, Kennedy SH, Lam RW, O'Donovan C, Filteau MJ, Parikh SV, et al. Canadian Network for Mood and Anxiety Treatments (CANMAT) clinical guidelines for the management of major depressive disorder in adults. I. Classification, burden and principles of management. J Affect Disord, 14. 2009;117(Suppl 1):S5

21. Health Quality Ontario. Major Depression: Care for Adults and Adolescents. Toronto, ON: Health Quality Ontario; 2016.

22. National Institute for Health Care Excellence. Depression in adults with a chronic physical health problem: recognition and management In: Guideline C, editor. 2009

23. Institute of Medicine Committee on the Crossing the Quality Chasm. Next Steps Toward a New Health Care S. In: Adams K, Greiner AC, Corrigan JM, editors. The 1st Annual Crossing the Quality Chasm Summit: A Focus on Communities. Washington (DC): National Academies Press (US); 2004.

24. McGowan P, Fredericks S, Beatty G. Strategies to Support Self-Management in Chronic Conditions: Collaboration with Clients. Toronto, ON: Registered Nurses Association of Ontario (RNAO); 2010.

25. Lorig KR, Holman H. Self-management education: history, definition, outcomes, and mechanisms. Ann Behav Med. 2003;26(1):1-7. https://doi. org/10.1207/S15324796ABM2601_01.

26. Bodenheimer T, Wagner EH, Grumbach K. Improving primary Care for Patients with Chronic IIness. JAMA. 2002;288(14):1775-9. https://doi.org/10.1 001/jama.288.14.1775.

27. Dineen-Griffin S, Garcia-Cardenas V, Williams K, Benrimoj SI. Helping patients help themselves: a systematic review of self-management support strategies in primary health care practice. PLoS One. 2019;14(8):e0220116. https://doi. org/10.1371/journal.pone.0220116.

28. Bodenheimer $\mathrm{T}$, Lorig $\mathrm{K}, \mathrm{Holman} \mathrm{H}$, Grumbach $\mathrm{K}$. Patient self-management of chronic disease in primary care. Jama. 2002;288(19):2469-75. https://doi. org/10.1001/jama.288.19.2469.

29. Bilsker D, Goldner EM, Anderson E. Supported self-management: a simple, effective way to improve depression care. Can J Psychiatry. 2012;57(4):2039. https://doi.org/10.1177/070674371205700402.

30. Lorig K. Chronic Disease Self-Management Program: Insights from the Eye of the Storm. Front Public Health. 2015;2:253.

31. Holman H, Lorig K. Patient self-management: a key to effectiveness and efficiency in care of chronic disease. Public Health Rep. 2004;119(3):239-43. https://doi.org/10.1016/j.phr.2004.04.002.

32. Ahn S, Basu R, Smith ML, Jiang L, Lorig K, Whitelaw N, et al. The impact of chronic disease self-management programs: healthcare savings through a community-based intervention. BMC Public Health. 2013;13(1):1141. https:// doi.org/10.1186/1471-2458-13-1141.

33. Lorig KR, Ritter P, Stewart AL, Sobel DS, Brown BW Jr, Bandura A, et al. Chronic disease self-management program: 2-year health status and health care utilization outcomes. Med Care. 2001;39(11):1217-23. https://doi.org/1 0.1097/00005650-200111000-00008.

34. Bower P, Richards D, Lovell K. The clinical and cost-effectiveness of self-help treatments for anxiety and depressive disorders in primary care: a systematic review. Br J Gen Pract. 2001;51(471):838-45.

35. Wagner EH, Austin BT, Davis $C$, Hindmarsh M, Schaefer J, Bonomi A. Improving chronic illness care: translating evidence into action. Health Aff 2001;20(6):64-78. https://doi.org/10.1377/hlthaff.20.6.64.

36. Adams K, Greiner AC, Corrigan JM. The 1st Annual Crossing the Quality Chasm Summit: A focus on communities. Washington, DC: National Academies Press; 2004.

37. Jones MC, MacGillivray S, Kroll T, Zohoor AR, Connaghan J. A thematic analysis of the conceptualisation of self-care, self-management and selfmanagement support in the long-term conditions management literature. J Nurs Healthc Chronic IIIn. 2011;3(3):174-85. https://doi.org/10.1111/j.17529824.2011.01096.x

38. Higgins JPT, Green SE. Cochrane Handbook for Systematic Reviews of Interventions Version 5.1.0 Higgins JPTG, S. (Eds). editor: The Cochrane Collabroation; 2011.

39. Moher D, Liberati A, Tetzlaff J, Altman DG. Preferred reporting items for systematic reviews and meta-analyses: the PRISMA statement. Ann Intern Med. 2009;151(4):264-9, w64. https://doi.org/10.7326/0003-4819-151-4-2 00908180-00135.

40. Beck AT, Steer RA, Carbin MG. Psychometric properties of the Beck depression inventory: twenty-five years of evaluation. Clin Psychol Rev. 1988; 8(1):77-100. https://doi.org/10.1016/0272-7358(88)90050-5.

41. Beck AT, Rush AJ, Shaw BF, Emery G. Cognitive therapy of depression. New York, NY: Guilford Press; 1979.

42. Beck AT, Steer RA, Brown GK. Manual for the Beck depression inventory-II. San Antonio, TX: Psychological Corporation; 1996.

43. Vilagut G, Forero CG, Barbaglia G, Alonso J. Screening for depression in the general population with the Center for Epidemiologic Studies Depression (CES-D): a systematic review with Meta-analysis. PLoS One. 2016;11(5): e0155431. https://doi.org/10.1371/journal.pone.0155431.

44. Radloff LS. The CES-D scale: a self-report depression scale for research in the general population. Appl Psychol Meas. 1977;1(3):385-401. https://doi.org/1 0.1177/014662167700100306

45. Kohout FJ, Berkman LF, Evans DA, Cornoni-Huntley J. Two shorter forms of the CES-D depression symptoms index. J Aging Health. 1993;5(2):179-93. https://doi.org/10.1177/089826439300500202.

46. Andresen EM, Malmgren JA, Carter WB, Patrick DL. Screening for depression in well older adults: evaluation of a short form of the CES-D (Center for Epidemiologic Studies Depression Scale). Am J Prev Med. 1994;10(2):77-84. https://doi.org/10.1016/S0749-3797(18)30622-6.

47. Hamilton M. A rating scale for depression. J Neurol Neurosurg Psychiatry. 1960;23(1):56-62. https://doi.org/10.1136/jnnp.23.1.56.

48. Zigmond AS, Snaith RP. The hospital anxiety and depression scale. Acta Psychiatr Scand. 1983;67(6):361-70. https://doi.org/10.1111/j.1600-0447.1983.tb09716.x.

49. Kroenke K, Spitzer RL, Williams JB. The PHQ-9: validity of a brief depression severity measure. J Gen Intern Med. 2001;16(9):606-13. https://doi.org/10.1 046/j.1525-1497.2001.016009606.x.

50. Yesavage JA, Brink TL, Rose TL, Lum O, Huang $V$, Adey $M$, et al. Development and validation of a geriatric depression screening scale: a preliminary report. J Psychiatr Res. 1982;17(1):37-49. https://doi.org/10.1016/ 0022-3956(82)90033-4.

51. American Psychiatric Association. Diagnostic Criteria from Dsm-lii-R. Washington, DC: American Psychiatric Association; 1980.

52. American Psychiatric Association. Diagnostic and statistical manual of mental disorders (3rd ed., revised). Washington, DC: American Psychiatric Association; 1987

53. American Psychiatric Association. Diagnostic Criteria from Dsm-Iv. Washington, DC: American Psychiatric Association; 1994.

54. American Psychiatric Association. Diagnostic and statistical manual of mental disorders (4th ed., text revision). Washington, DC: American Psychiatric Association; 2000.

55. American Psychiatric Association. Diagnostic and statistical manual of mental disorders (5th ed.). Washington, DC: American Psychiatric Association; 2013. https://doi.org/10.5555/appi.books.9780890425596. xo0pre.

56. World Health Organization (WHO). International Classification of Disease (ICD-9). Geneva: World Health Organization; 1977. 
57. World Health Organization. The ICD-10 classification of mental and behavioural disorders: clinical descriptions and diagnostic guidelines. Geneva: World Health Organization; 1992.

58. Public Health Agency of Canada. The Canadian Chronic Disease Surveillance System - An Overview. Government of Canada; 2021. https://www.canada. ca/en/public-health/services/publications/canadian-chronic-disease-surveilla nce-system-factsheet.html.

59. Drug and Therapeutics Bulletin. Management of seasonal affective disorder. BMJ. 2010;340:c2135.

60. Kurlansik SL, Ibay AD. Seasonal affective disorder. Am Fam Physician. 2012; 86(11):1037-41.

61. Muller-Oerlinghausen B, Berghofer A, Bauer M. Bipolar disorder. Lancet (London, England). 2002;359(9302):241-7.

62. O'Hara MW, Wisner KL. Perinatal mental illness: definition, description and aetiology. Best Pract Res Clin Obstet Gynaecol. 2014;28(1):3-12. https://doi. org/10.1016/j.bpobgyn.2013.09.002.

63. British Colombia Partners for Mental Health and Addictions Information (BC Partners). Depression Toolkit: Information and Resources for Effective SelfManagement of Depression. 2003. http://www.gpscbc.ca/sites/default/files/ uploads/AMH_212.0_Depression_Toolkit_PR.pdf.

64. Bilsker D, Paterson R. Antidepressant skills workbook. Vancouver, BC: Simon Fraser University; 2005.

65. Houle J, Gascon-Depatie M, Bélanger-Dumontier G, Cardinal C. Depression self-management support: a systematic review. Patient Educ Couns. 2013; 91(3):271-9. https://doi.org/10.1016/j.pec.2013.01.012.

66. Regan T, Lambert SD, Kelly B. Uptake and attrition in couple-based interventions for cancer: perspectives from the literature. Psycho-Oncology. 2013;22(12):2639-47. https://doi.org/10.1002/pon.3342.

67. McGowan J, Sampson M, Salzwedel DM, Cogo E, Foerster V, Lefebvre C. PRESS peer review of electronic search strategies: 2015 guideline statement. J Clin Epidemiol. 2016;75:40-6. https://doi.org/10.1016/j.jclinepi.2016.01.021.

68. Bramer WM, Giustini D, de Jonge GB, Holland L, Bekhuis T. De-duplication of database search results for systematic reviews in EndNote. J Med Library Assoc. 2016;104(3):240-3. https://doi.org/10.3163/1536-5050.104.3.014.

69. Schaffler J, Leung K, Tremblay S, Merdsoy L, Belzile E, Lambrou A, et al. The effectiveness of self-management interventions for individuals with low health literacy and/or low income: a descriptive systematic review. J Gen Intern Med. 2018;33(4):510-23. https://doi.org/10.1007/s11606-01 7-4265-x.

70. Lambert S, Ould Brahim L, McCusker J, Coumoundouros C, Audet L, Yaffe M, et al. Non-pharmacological interventions for caregivers with depression and caregivers of care recipients with co-morbid depression: A systematic review and meta-analysis. Manuscript submitted for publication. 2020.

71. Higgins JPT SJ, Savović J, Page MJ, Hróbjartsson A, Boutron I, Reeves B, Eldridge $S$. A revised tool for assessing risk of bias in randomized trials. 2016. In: Cochrane Database Syst Rev. [Suppl 1]. Available from: dx.doi.org/ https://doi.org/10.1002/14651858.CD201601.

72. Hedges LV, Olkin I. Statistical methods for meta-analysis. Orlando: Academic Press; 1985.

73. Cooper HM, Hedges LV, Valentine JC. Handbook of research synthesis and meta-analysis. New York: Russell Sage Foundation; 2019. http://www.jstor. org/stable/https://doi.org/10.7758/9781610448864. Available from: https:// muse.jhu.edu/book/65827/. http://www.vlebooks.com/vleweb/product/ openreader?id=none\&isbn=9781610448864.

74. Cohen J. Statistical power analysis for the behavioral sciences. 2nd edition ed. New York, NY: Lawrence Erlbaum Associates; 1988.

75. Cornell JE, Mulrow CD, Localio R, Stack CB, Meibohm AR, Guallar E, et al. Random-effects meta-analysis of inconsistent effects: a time for change. Ann Intern Med. 2014;160(4):267-70. https://doi.org/10.7326/M13-2886.

76. Kraemer HC, Wilson GT, Fairburn CG, Agras WS. Mediators and moderators of treatment effects in randomized clinical trials. Arch Gen Psychiatry. 2002; 59(10):877-83. https://doi.org/10.1001/archpsyc.59.10.877.

77. Fu R, Gartlehner G, Grant M, Shamliyan T, Sedrakyan A, Wilt TJ, et al. Conducting quantitative synthesis when comparing medical interventions: AHRQ and the effective health care program. J Clin Epidemiol. 2011;64(11): 1187-97. https://doi.org/10.1016/j.jclinepi.2010.08.010.

78. Barley EA, Walters P, Haddad M, Phillips R, Achilla E, McCrone P, et al. The UPBEAT nurse-delivered personalized care intervention for people with coronary heart disease who report current chest pain and depression: a randomised controlled pilot study. PLoS One. 2014;9(6):e98704. https://doi. org/10.1371/journal.pone.0098704.
79. Tylee A, Barley EA, Walters P, Achilla E, Borschmann R, Leese M, et al. Programme Grants for applied research. UPBEAT-UK: a programme of research into the relationship between coronary heart disease and depression in primary care patients. Southampton (UK): NIHR Journals Library; 2016.

80. Boele FW, Klein M, Verdonck-de Leeuw IM, Cuijpers P, Heimans JJ, Snijders TJ, et al. Internet-based guided self-help for glioma patients with depressive symptoms: a randomized controlled trial. J Neuro-Oncol. 2018;137(1):191203. https://doi.org/10.1007/s11060-017-2712-5.

81. Boele FW, Verdonck-de Leeuw IM, Cuijpers P, Reijneveld JC, Heimans JJ, Klein M. Internet-based guided self-help for glioma patients with depressive symptoms: design of a randomized controlled trial. BMC Neurol. 2014;14(1): 81. https://doi.org/10.1186/1471-2377-14-81

82. Espahbodi F, Hosseini H, Mirzade MM, Shafaat AB. Effect of psycho education on depression and anxiety symptoms in patients on hemodialysis. Iran J Psychiatry Behav Sci. 2015;9(1):e227-e.

83. Fischer A, Schröder J, Vettorazzi E, Wolf OT, Pöttgen J, Lau S, et al. An online programme to reduce depression in patients with multiple sclerosis: a randomised controlled trial. Lancet Psychiatry. 2015;2(3):217-23. https://doi. org/10.1016/\$2215-0366(14)00049-2.

84. Lamers F, Jonkers CC, Bosma H, Kempen Gl, Meijer JA, Penninx BW, et al. A minimal psychological intervention in chronically ill elderly patients with depression: a randomized trial. Psychother Psychosom. 2010;79(4):217-26. https://doi.org/10.1159/000313690.

85. Lamers F, Jonkers CC, Bosma H, Diederiks JP, van Eijk JT. Effectiveness and cost-effectiveness of a minimal psychological intervention to reduce nonsevere depression in chronically ill elderly patients: the design of a randomised controlled trial [ISRCTN92331982]. BMC Public Health. 2006;6(1): 161. https://doi.org/10.1186/1471-2458-6-161.

86. Lamers F, Jonkers CC, Bosma H, Chavannes NH, Knottnerus JA, van Eijk JT. Improving quality of life in depressed COPD patients: effectiveness of a minimal psychological intervention. Copd. 2010;7(5):315-22. https://doi. org/10.3109/15412555.2010.510156

87. Lamers F, Jonkers CC, Bosma H, Knottnerus JA, van Eijk JT. Treating depression in diabetes patients: does a nurse-administered minimal psychological intervention affect diabetes-specific quality of life and glycaemic control? A randomized controlled trial. J Adv Nurs. 2011;67(4): 788-99. https://doi.org/10.1111/j.1365-2648.2010.05540.x.

88. Lee JY, Park HY, Jung D, Moon M, Keam B, Hahm BJ. Effect of brief psychoeducation using a tablet PC on distress and quality of life in cancer patients undergoing chemotherapy: a pilot study. Psychooncology. 2014; 23(8):928-35. https://doi.org/10.1002/pon.3503.

89. Moncrieft AE, Llabre MM, McCalla JR, Gutt M, Mendez AJ, Gellman MD, et al. Effects of a multicomponent life-style intervention on weight, glycemic control, depressive symptoms, and renal function in low-income, minority patients with type 2 diabetes: results of the community approach to lifestyle modification for diabetes randomized controlled trial. Psychosom Med. 2016;78(7):851-60. https://doi.org/10.1097/PSY.0000000000000348.

90. Penckofer SM, Ferrans C, Mumby P, Byrn M, Emanuele MA, Harrison PR, et al. A psychoeducational intervention (SWEEP) for depressed women with diabetes. Ann Behav Med. 2012;44(2):192-206. https://doi.org/10.1007/s12160-012-9377-2.

91. Rees G, O'Hare F, Saeed M, Sudholz B, Sturrock BA, Xie J, et al. Problemsolving therapy for adults with diabetic retinopathy and diabetes-specific distress: a pilot randomized controlled trial. BMJ Open Diabetes Res Care. 2017;5(1):e000307. https://doi.org/10.1136/bmjdrc-2016-000307.

92. Schröder J, Brückner K, Fischer A, Lindenau M, Köther U, Vettorazzi E, et al. Efficacy of a psychological online intervention for depression in people with epilepsy: a randomized controlled trial. Epilepsia. 2014;55(12):2069-76. https://doi.org/10.1111/epi.12833.

93. Sharpe M, Strong V, Allen K, Rush R, Maguire P, House A, et al. Management of major depression in outpatients attending a cancer Centre: a preliminary evaluation of a multicomponent cancer nurse-delivered intervention. $\mathrm{Br} J$ Cancer. 2004;90(2):310-3. https://doi.org/10.1038/sj.bjc.6601546.

94. Sharpe M, Walker J, Hansen CH, Martin P, Symeonides S, Gourley C, et al. Integrated collaborative care for comorbid major depression in patients with cancer (SMaRT Oncology-2): a multicentre randomised controlled effectiveness trial. Lancet. 2014;384(9948):1099-108. https://doi.org/10.1016/ S0140-6736(14)61231-9.

95. Strong V, Waters R, Hibberd C, Murray G, Wall L, Walker J, et al. Management of depression for people with cancer (SMaRT oncology 1): a randomised trial. Lancet. 2008;372(9632):40-8. https://doi.org/10.1016/S01406736(08)60991-5. 
96. Thornton LM, Andersen BL, Schuler TA, Carson WE 3rd. A psychological intervention reduces inflammatory markers by alleviating depressive symptoms: secondary analysis of a randomized controlled trial. Psychosom Med. 2009;71(7):715-24. https://doi.org/10.1097/PSY.0b013e3181b0545c

97. Walker J, Hansen CH, Martin P, Symeonides S, Gourley C, Wall L, et al. Integrated collaborative care for major depression comorbid with a poor prognosis cancer (SMaRT Oncology-3): a multicentre randomised controlled trial in patients with lung cancer. Lancet Oncol. 2014;15(10):1168-76. https://doi.org/10.1016/S1470-2045(14)70343-2.

98. Derogatis LR. The SCL-90 manual I: scoring, administration and procedures for the SCL-90. Baltimore, MD: Clinical psychometric research; 1977.

99. O'Connor M, Butcher I, Hansen CH, Kleiboer A, Murray G, Sharma N, et al. Measuring improvement in depression in cancer patients: a 50\% drop on the self-rated SCL-20 compared with a diagnostic interview. Gen Hosp Psychiatry. 2010;32(3):334-6. https://doi.org/10.1016/j. genhosppsych.2010.01.001.

100. Cuijpers P, van Straten A, Bohlmeijer E, Hollon S, Andersson G. The effects of psychotherapy for adult depression are overestimated: a meta-analysis of study quality and effect size. Database of Abstracts of Reviews of Effects (DARE): Quality-assessed Reviews [Internet]: Centre for Reviews and Dissemination (UK); 2010.

101. Hunsley J, Elliott K, Therrien Z. The efficacy and effectiveness of psychological treatments for mood, anxiety, and related disorders. Can Psychol. 2014;55(3):161-76. https://doi.org/10.1037/a0036933.

102. Cuijpers P, Clignet F, van Meijel B, van Straten A, Li J, Andersson G. Psychological treatment of depression in inpatients: a systematic review and meta-analysis. Clin Psychol Rev. 2011;31(3):353-60. https://doi.org/10.1 016/j.cpr.2011.01.002.

103. Cuijpers P, Kleiboer AM, DeRubeis RJ, Strunk DR. Self-directed approaches to the treatment of depression. In: The Oxford handbook of mood disorders. Oxford: Oxford University Press; 2017. p. 469-77. https://doi.org/10.1093/ oxfordhb/9780199973965.013.40.

104. Van't Hof E, Cuijpers P, Stein DJ. Self-help and internet-guided interventions in depression and anxiety disorders: a systematic review of meta-analyses. CNS Spectr. 2009;14(2 Suppl 3):34-40. https://doi.org/10.1017/S1092852 900027279.

105. Gyani A, Shafran R, Layard R, Clark DM. Enhancing recovery rates: lessons from year one of IAPT. Behav Res Ther. 2013;51(9):597-606. https://doi.org/1 0.1016/j.brat.2013.06.004.

106. McCusker CMG. Yaffe M, Strumpf E, Sewitch M, Sussman T, et al. a randomized trial of a depression self-care toolkit with or without lay telephone coaching for primary care patients with chronic physical conditions. Gen Hosp Psychiatry. 2015;37(3):257-65. https://doi.org/10.1016/ j.genhosppsych.2015.03.007.

107. Simco R, McCusker J, Sewitch M. Adherence to self-care interventions for depression or anxiety: a systematic review. Health Educ J. 2014;73(6):714-30. https://doi.org/10.1177/0017896913514738.

108. Donkin L, Christensen H, Naismith SL, Neal B, Hickie IB, Glozier N. A systematic review of the impact of adherence on the effectiveness of etherapies. J Med Internet Res. 2011;13(3):e52. https://doi.org/10.2196/jmir.1 772.

109. Schulz KF, Grimes DA. Sample size slippages in randomised trials: exclusions and the lost and wayward. Lancet (London, England). 2002;359(9308):781-5.

110. Nunan D, Aronson J, Bankhead C. Catalogue of bias: attrition bias. Bmj Evid Based Med. 2018;23(1):21-2. https://doi.org/10.1136/ebmed-2017-110883.

111. Dumville JC, Torgerson DJ, Hewitt CE. Reporting attrition in randomised controlled trials. BMJ. 2006;332(7547):969-71. https://doi.org/10.1136/ bmj.332.7547.969.

112. Warden D, Rush AJ, Carmody TJ, Kashner TM, Biggs MM, Crismon ML, et al. Predictors of attrition during one year of depression treatment: a roadmap to personalized intervention. J Psychiatr Pract. 2009;15(2):113-24. https://doi. org/10.1097/01.pra.0000348364.88676.83.

113. Warden D, Trivedi MH, Wisniewski SR, Davis L, Nierenberg AA, Gaynes BN, et al. Predictors of attrition during initial (citalopram) treatment for depression: a STAR*D report. Am J Psychiatry. 2007;164(8):1189-97. https:// doi.org/10.1176/appi.ajp.2007.06071225.

114. Lambert SD, Clover K, Pallant JF, Britton B, King MT, Mitchell AJ, et al. Making sense of variations in prevalence estimates of depression in Cancer: a co-calibration of commonly used depression scales using Rasch analysis. J Natl Compr Cancer Netw. 2015;13(10):1203-11. https://doi.org/10.6004/ jnccn.2015.0149.
115. van Straten A, Seekles W, van't Veer-Tazelaar NJ, Beekman AT, Cuijpers P. Stepped care for depression in primary care: what should be offered and how? Med J Aust. 2010;192(11):S36

116. Bower P, Gilbody S. Stepped care in psychological therapies: access, effectiveness and efficiency. Br J Psychiatry. 2005;186(1):11-7. https://doi. org/10.1192/bjp.186.1.11.

117. van Grieken RA, Kirkenier ACE, Koeter MWJ, Schene AH. Helpful selfmanagement strategies to cope with enduring depression from the patients' point of view: a concept map study. BMC Psychiatry. 2014;14:331.

118. van Grieken RA, Kirkenier AC, Koeter MW, Nabitz UW, Schene AH. Patients' perspective on self-management in the recovery from depression. Health Expect. 2015;18(5):1339-48. https://doi.org/10.1111/hex.12112.

119. Michie S, Johnston M, Francis J, Hardeman W, Eccles M. From theory to intervention: mapping theoretically derived Behavioural determinants to behaviour change techniques. Appl Psychol. 2008;57(4):660-80. https://doi. org/10.1111/j.1464-0597.2008.00341.x.

120. Lambert SD, Beatty L, McElduff $P$, Levesque JV, Lawsin C, Jacobsen $P$, Turner J, Girgis A. A systematic review and meta-analysis of written selfadministered psychosocial interventions among adults with a physical illness. Patient education and counseling. 2017;100(12):2200-17. https://doi. org/10.1016/j.pec.2017.06.039.

121. Cuijpers P, Donker T, Johansson R, Mohr DC, van Straten A, et al. SelfGuided Psychological Treatment for Depressive Symptoms: A Meta-Analysis. PLOS ONE. 2011;6(6):e21274. https://doi.org/10.1371/journal.pone.0021274.

\section{Publisher's Note}

Springer Nature remains neutral with regard to jurisdictional claims in published maps and institutional affiliations.
Ready to submit your research? Choose BMC and benefit from:

- fast, convenient online submission

- thorough peer review by experienced researchers in your field

- rapid publication on acceptance

- support for research data, including large and complex data types

- gold Open Access which fosters wider collaboration and increased citations

- maximum visibility for your research: over $100 \mathrm{M}$ website views per year

At BMC, research is always in progress.

Learn more biomedcentral.com/submissions 